University of Louisville

ThinkIR: The University of Louisville's Institutional Repository

Electronic Theses and Dissertations

$12-2019$

\title{
Police stress, depression, and substance use among police officers: a general strain perspective.
}

Kyra Nicole Fritz

University of Louisville

Follow this and additional works at: https://ir.library.louisville.edu/etd

Part of the Criminology and Criminal Justice Commons

\section{Recommended Citation}

Fritz, Kyra Nicole, "Police stress, depression, and substance use among police officers: a general strain perspective." (2019). Electronic Theses and Dissertations. Paper 3325.

https://doi.org/10.18297/etd/3325

This Doctoral Dissertation is brought to you for free and open access by ThinkIR: The University of Louisville's Institutional Repository. It has been accepted for inclusion in Electronic Theses and Dissertations by an authorized administrator of ThinkIR: The University of Louisville's Institutional Repository. This title appears here courtesy of the author, who has retained all other copyrights. For more information, please contact thinkir@louisville.edu. 


\title{
POLICE STRESS, DEPRESSION, AND SUBSTANCE USE AMONG POLICE OFFICERS: \\ A GENERAL STRAIN PERSPECTIVE
}

\author{
By \\ Kyra Nicole Fritz \\ B.A., University of Kansas, 2011 \\ M.A., Spalding University, 2016

\begin{abstract}
A Dissertation
Submitted to the Faculty of the

College of Arts and Sciences of the University of Louisville in Partial Fulfillment of the Requirements

for the Degree of
\end{abstract} \\ Doctor of Philosophy \\ in Criminal Justice \\ Department of Criminal Justice \\ University of Louisville \\ Louisville, Kentucky
}

December 2019 
Copyright 2019 by Kyra Nicole Fritz

All rights reserved 



\section{POLICE STRESS, DEPRESSION, AND SUBSTANCE USE AMONG POLICE OFFICERS: \\ A GENERAL STRAIN PERSPECTIVE}

\section{By}

Kyra Nicole Fritz

B.A., University of Kansas, 2011

M.A., Spalding University, 2016

A Dissertation Approved on

November 11, 2019

by the following Dissertation Committee:

Dr. George E. Higgins

Dr. Gennaro F. Vito

Dr. Viviana Andreescu

Dr. Seana Golder 


\section{DEDICATION}

For my husband, Andy, without whom, I would not have had the courage to embark on this life-changing journey. 


\title{
ACKNOWLEDGMENTS
}

\begin{abstract}
A very big thank you to my mentor, Dr. George E. Higgins, for his expertise, guidance, patience, and encouragement throughout the arduous process of completing this dissertation. I would also like to thank my committee members, Dr. Gennaro F. Vito, Dr. Viviana Andreescu, and Dr. Seana Golder, for their many helpful comments and suggestions along the way.
\end{abstract}

I would like to extend my sincerest gratitude to my colleagues at the Pacific Institute for Research and Evaluation (PIRE). Without their unwavering support and encouragement, completing this dissertation would not have been possible. 


\section{ABSTRACT \\ POLICE STRESS, DEPRESSION, AND SUBSTANCE USE}

AMONG POLICE OFFICERS:

A GENERAL STRAIN PERSPECTIVE

Kyra Nicole Fritz

November 11, 2019

This dissertation examines the utility of general strain theory in explaining substance use as a form of coping among a sample of police officers in a Midwestern, metropolitan city. The dissertation is comprised of five chapters, including the introduction, literature review, method, results, and discussion. Chapter one describes the stressful nature of a career in law enforcement, concentrating on the adverse consequences of prolonged stress, including depression and substance use. Chapter one also examines strain, depression, and substance use among police officers using a general strain perspective, highlighting the limitations of existing empirical studies. Chapter two details the theoretical premise in relation to strain, depression, and substance use and also presents empirical evidence for general strain theory. Chapter three describes the data, sample, measures, and analytic strategy that will be used. In particular, participants were surveyed regarding their demographic characteristics, levels of strain, symptoms of depression, and frequency of substance use as a form of coping. Structural equation modeling will be used to analyze multiple research hypotheses among the latent measures of strain, depression, and substance use as a form of coping simultaneously. Chapter four 
describes the results of the data analyses. Chapter five discusses the anticipated findings within the context of the theoretical premise; provides policy implications; and highlights study limitations and directions for future research. 
TABLE OF CONTENTS

PAGE

ACKNOWLEDGMENTS …………......................................................... iv

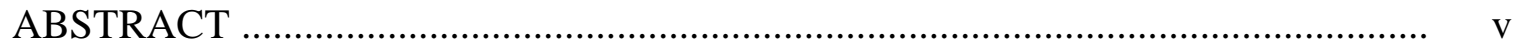

LIST OF TABLES ……………….............................................................. vii

LIST OF FIGURES ..................................................................................... ix

CHAPTER 1: INTRODUCTION ........................................................................

CHAPTER II: LITERATURE REVIEW ............................................................

CHAPTER III: METHOD ........................................................................... 40

CHAPTER IV: RESULTS _...................................................................................... 56

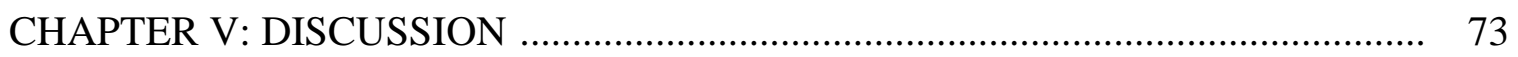

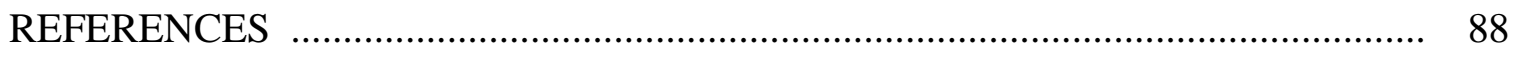

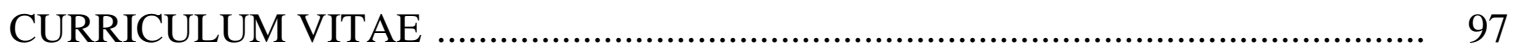




\section{LIST OF TABLES}

TABLE

PAGE

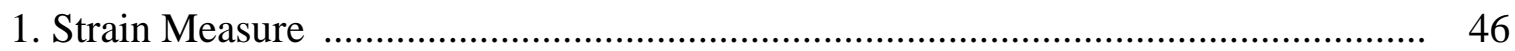

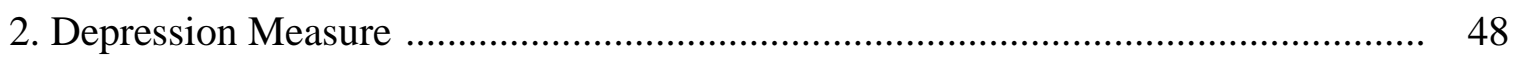

3. Substance Use as Coping Measure ………………............................................ 49

4. Sociodemographic Characteristics .............................................................. 50

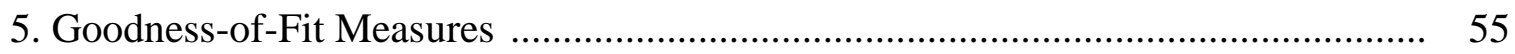

6. Comparison of Study Sample and Nationally Representative Sample .................... 57

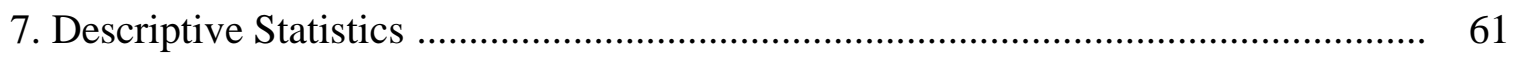

8. Polychoric Correlation Matrix ………………………....................................... 64

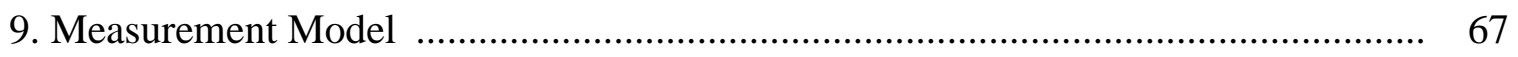

10. Indirect Effects Structural Model 1 .............................................................. 69

11. Direct Effects Structural Model 2 _............................................................... 70

12. Direct and Indirect Effects Structural Model 3 _.................................................. 72 


\section{LIST OF FIGURES}

PAGE

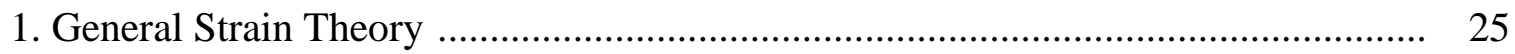

2. Direct and Indirect Effects Theoretical Model ……............................................. 39

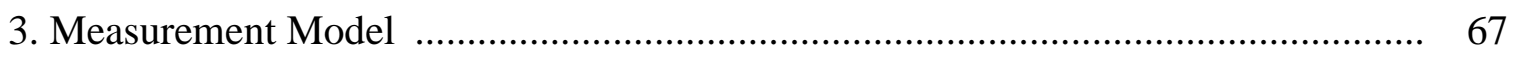

4. Indirect Effects Structural Model 1 _................................................................. 69

5. Direct Effects Structural Model 2 _............................................................... 70

6. Direct and Indirect Effects Structural Model 3 ........................................................ 72 


\section{CHAPTER I}

\section{INTRODUCTION}

A career in law enforcement is considerably more stressful than many other occupations (Anshel, 2000; Bishopp \& Boots, 2014; Gershon, Lin, \& Li, 2002; Gibson, Swatt, \& Jolicoeur, 2001; Moon \& Jonson, 2012; Swatt, Gibson, \& Piquero, 2007; Wang et al., 2010). Prolonged stress can cause detrimental damage to police officers if left untreated. Indeed, repeated exposure to strain has been linked to many adverse biological and psychological health outcomes, including depression. Depression is increasingly regarded as an abnormality of stress adaptation systems in the brain, and its prevalence has been observed at a higher rate among police officers compared to the general public (Wang et al., 2010). Depression is commonly linked to various aspects of strain among new recruits (Wang et al., 2010) and veteran police officers, like chronic workplace violence (Lee, Kim, \& Kim, 2014), critical incidents, organizational factors (Gershon et al., 2002), negative work characteristics, limited positive work factors, and inadequate support from colleagues (Nelson \& Smith, 2016) among others. In order to reduce or eliminate felt strain, police officers rely on various cognitive, behavioral, and emotional coping strategies.

Substance use is frequently cited in existing police literature as a maladaptive coping strategy among officers to deliberately or inadvertently regulate negative 
emotional states produced by strain (Dietrich \& Smith, 1986; Smith, Devine, Leggat, \& Ishitake, 2005). The pervasiveness of substance use among officers in direct response to strain is well-documented across historical and international boundaries. Indeed, several researchers (Chopko, Palmieri, \& Adams, 2013; Smith et al., 2005; Swatt et al., 2007) observed a higher rate of substance use among police officers compared to the general public. Police officers commonly use caffeine, nicotine, alcohol, barbiturates, benzodiazepines, cannabis, and opioids to manage depression and anxiety (Amaranto, Steinberg, Castellano, \& Mitchell, 2003), though most existing police literature discussed the prevalence, predictors, or outcomes of problematic alcohol consumption. For example, researchers identified that female police officers (Ballenger et al., 2011) and those between 18 and 39 years of age (Richmond, Wodak, Kehoe, \& Heather, 1998) had a greater risk of developing binge-drinking behaviors than the general public. Other studies (Davey, Obst, \& Sheehan, 2000; Van Raalte, 1979) determined that between 26\% and $67 \%$ of police officers consumed alcohol while on-duty.

Undoubtedly, police officers who do not incorporate effective coping strategies to alleviate strain are at an increased risk of developing depressive and substance use disorders. Given the impact of police stress on officer safety and public health, understanding how officers respond to strain is critical. While there is an abundance of existing police literature describing the negative effects of strain, studies rarely progressed beyond the simple risk factor approach. The lack of theoretically-informed research examining the complex causal mechanisms that underlie strain, depression, and substance use among police officers do not allow researchers and practitioners to develop effective strain prevention, intervention, and training programs (Swatt et al., 2007). If 
there is any hope to extend our understanding of how these constructs interact, it is necessary to explore them using theory. Robert Agnew's (1992) general strain theory (GST) may provide such a framework.

Agnew (1992) proposed a general theory of crime that expanded on classic strain theory. While classic strain theory primarily focused on structural-level influences to explain delinquency and crime in American society, Agnew developed a socialpsychological approach that concentrated on individuals and their immediate social environment (Agnew 1992; Agnew \& White, 1992). Strain was defined as an event or condition that was disliked by individuals (Agnew, 2006). Agnew (1992) outlined three primary types of strain that lead to crime, including "(1) the actual or anticipated failure to achieve positively valued goals, (2) the actual or anticipated removal of positively valued stimuli, and (3) the actual or anticipated presentation of negative stimuli" (p. 74). Agnew (1992) argued that it was vital to properly measure each type of strain when testing predictions of GST. General guidelines for the proper measurement of strain were proposed, like developing a comprehensive list of negative relations (i.e., identify objective and subjective strains); exploring the cumulative impact of negative relations (i.e., use a composite index of strain or study the interactions among strain measures); and examining the magnitude (i.e., size), recency (i.e., recency of adverse events), duration (i.e., chronic stressors), and clustering (i.e., events clustered closely in time) of adverse events (Agnew, 1992).

Negative emotional states resulted when individuals encountered strain, such as anger, frustration, jealousy, malicious envy, depression, fear, shame, and alienation (Agnew, 1992; Agnew, 2006; Agnew \& White, 1992; Swatt et al., 2007). Negative 
emotional states produced pressure for corrective action to reduce or eliminate felt strain. In other words, negative emotional states prepared individuals to engage in various coping strategies to lessen negative affect produced by strain (Swatt et al., 2007). Agnew (2006) argued that negative emotional states decreased the ability to legally cope and reduced the perceived cost of crime, creating a disposition for delinquency and crime. Agnew (1992) introduced a typology of three broad adaptations to strain, each acting as a mechanism to reduce or eliminate negative emotional states produced by strain. Cognitive coping strategies consisted of reinterpreting objective strains in ways that minimized their subjective adversity (Agnew, 1992; Agnew, 2006; Swatt et al., 2007). Behavioral coping strategies consisted of employing delinquent or conventional behaviors to minimize or eliminate adversity or extract revenge upon the stressors (Agnew, 1992; Swatt et al., 2007). Emotional coping strategies consisted of acting directly upon emotions to alleviate negative emotional states caused by adversity versus cognitively reinterpreting or behaviorally modifying the strains that produced the emotions (Agnew, 1992; Agnew, 2006; Swatt et al., 2007). Agnew (1992) suggested that emotional coping was more likely to occur if cognitive and behavioral coping strategies were unavailable or ineffective. Additionally, individuals could make little or no effort to cope with their strains or use a broad range of coping strategies simultaneously (Agnew, 1992; Agnew, 2006; Swatt et al., 2007).

According to Agnew (2006), individuals reacted to strains with delinquency and crime depending on the types of strains experienced, personal features, and environmental factors. Specific individual and environmental characteristics reduced the likelihood of legal behavioral coping and undermined the effectiveness of emotional and 
cognitive coping. Factors that increased the likelihood of criminal coping included poor coping skills and resources (e.g., problem-solving, social skills, sociodemographic characteristics, self-efficacy) and low levels of conventional social support (i.e., assistance from conventional others) (Agnew, 2006).

GST has been applied by researchers to explore characteristics of strain, negative emotional states, and coping strategies known to cultivate delinquency, crime, and maladaptive behaviors among adolescent, college, and police officer samples. Although the results obtained in these studies offered support for GST, many failed to measure strain properly. For example, many researchers assessed strain with non-validated measures, limited items, or simplistic measures that did not consider various dimensions or characteristics of strain. Additionally, prior research relied heavily on traditional regression analyses to test hypotheses. The noted limitations increase measurement error and the possibility that other factors not considered in the analyses could account for observed relationships.

The purpose of the current study is to overcome limitations of prior empirical studies. The current research contributes to the empirical development of GST by testing the framework using new sample data, a validated strain measure, and rigorous statistical methods. Different from police strain measures examined in prior GST studies (e.g., Bishopp, Piquero, Worrall, \& Piquero, 2018; Gibson et al., 2001; Kurtz, Zavala, \& Melander, 2015; Moon \& Jonson, 2012; Shim, Joe, \& Hoover, 2015; Swatt et al., 2007; Yun \& Lee, 2015), the current study includes a strain measure capturing multiple types of strain unique to the policing context. The investigation examines the mediating effect of depression on the relationship between strain (i.e., financial problems, time away from 
family, and media scrutiny) and substance use as a form of coping among a sample of Midwestern police officers using structural equation modeling (SEM). Informed by the tenets of GST, it is expected that strain will directly impact substance use as a form of coping or that its effects will be mediated by depression. 


\section{CHAPTER II}

\section{LITERATURE REVIEW}

\section{Police Stress, Depression, and Substance Use}

Working in the field of law enforcement is significantly more stressful than many other professions (Anshel, 2000; Bishopp \& Boots, 2014; Gershon et al., 2002; Gibson et al., 2001; Moon \& Jonson, 2012; Swatt et al., 2007; Wang et al., 2010). Interestingly, some researchers (Bishopp \& Boots, 2014; Moon \& Jonson, 2012; Swatt et al., 2007) argue that stress is a natural and unavoidable aspect of policing as officers frequently encounter significant forms of strain that other occupations rarely experience. Since the police profession is inherently stressful, it is common for officers to report a variety of health problems. The fight-or-flight mode is activated when police officers experience stress, in which the body releases an excess of cortisol. Indeed, the mere potential of experiencing stressful workplace events is enough to flood the body with cortisol for an indeterminate amount of time, even when no danger is present. Adverse biological and psychological health outcomes result when cortisol levels do not return to baseline functioning (Akinola \& Mendes, 2012; Anshel, 2000; Hickman, Fricas, Strom, \& Pope, 2011).

Depression is frequently cited as an adverse psychological health outcome of strain in existing police literature. Depression is increasingly regarded as an abnormality 
of stress adaptation systems in the brain. Strain disrupts police officers' neuroendocrine systems, which could lead to the development of a depressive disorder. Rates and symptoms of depression have been observed at a higher rate among police officers compared to the general public (Wang et al., 2010). For example, a longitudinal study conducted by Wang et al. (2010) determined that police recruits who experienced greater perceived work stress demonstrated greater levels of depression symptoms after their first year of service. Additionally, a higher prevalence of depressive symptomatology was observed among police officers who experienced chronic workplace violence in another study (Lee et al., 2014). Other empirical findings revealed that depression was significantly associated with critical incidents, organizational factors (e.g., poor cooperation, inequality) (Gershon et al., 2002), negative work characteristics (e.g., demand, effort, consultation on change, over-commitment), limited positive work factors (e.g., reward, control), and inadequate work support (e.g., colleague support, supervisor support, supervisor relationship, bullying) (Nelson \& Smith, 2016) among police officers. In order to alleviate felt strain, police officers frequently use a range of cognitive, behavioral, and emotional coping strategies.

Substance use is frequently identified in existing police literature as a maladaptive coping strategy employed by officers to deliberately or inadvertently regulate negative emotional states produced by strain (Dietrich \& Smith, 1986; Smith et al., 2005). In their study on occupational stress and non-medical use of drugs and alcohol among police officers, Dietrich and Smith (1986) suggested that substances are "not only used but very much accepted as a way of coping with tensions and stresses of the day" (p. 304). Indeed, the pervasiveness of substance use among police officers in direct response to 
strain is well-documented across historical and international boundaries, in which several studies (Chopko et al., 2013; Smith et al., 2005; Swatt et al., 2007) concluded that this population used substances at a higher rate compared to the general public. Although stimulants (i.e., caffeine, nicotine, sugar) and depressants (i.e., alcohol, barbiturates, benzodiazepines, cannabis, opioids) are among the most common substances used by police officers to manage depression and anxiety (Amaranto et al., 2003), most existing police literature discussed the prevalence, predictors, or outcomes of problematic alcohol consumption. For example, Ballenger et al. (2011) evaluated the patterns and predictors of alcohol use in a sample of 747 urban police officers. Results revealed that police officers were more likely to binge-drink than the general public, with female officers being two to three times more likely.

In another large cross-sectional study, Richmond et al. (1998) examined gender differences with respect to alcohol use among a sample of Australian police officers. Results indicated that $48 \%$ of males and $40 \%$ of females consumed alcohol excessively. Additionally, police officers between 18 and 39 years of age had a greater risk of developing binge-drinking behaviors. Violanti et al. (2011) investigated alcohol use correlates and psychological outcomes of stress related to the use and level of alcohol among a sample of 115 police officers. Results suggested that $63.9 \%$ of the sample exceeded the World Health Organization's (WHO) daily recommended amount of alcohol. A cross-sectional study conducted by Davey et al. (2000) explored the prevalence of alcohol use among a sample of 4,193 police officers from an Australian state police service. Results demonstrated that police officers reported greater quantities of alcohol consumption than the general public. More specifically, $35 \%$ of both males 
and females participated in binge-drinking, which were higher rates than those reported in previous studies using the WHO criterion at that time. Alarmingly, 26\% of the sample reported drinking while on-duty. Likewise, a study by Van Raalte (1979) determined that $67 \%$ of police officers working the night shift reported drinking alcohol while on-duty.

Undoubtedly, police officers who do not utilize effective coping strategies to lessen strain are at an increased risk of developing depressive and substance use disorders. Considering the impact of police stress on officer safety and public health, understanding how officers respond to strain is crucial. Despite the plethora of existing police literature discussing the adverse outcomes of strain, studies rarely progressed beyond the simple risk factor approach. The lack of theoretically-informed research examining the causal links that underlie strain, depression, and substance use among police officers do not allow researchers and practitioners to create effective strain prevention, intervention, and training programs (Swatt et al., 2007). If there is any hope to extend our understanding of how these constructs interact, it is essential to examine them using theory. Agnew's (1992) general strain theory (GST) may provide such a framework.

\section{Theoretical Framework}

History of general strain theory. The origin of strain theory dates back to Emile Durkheim's (1893) concept of anomie. Durkheim (1893) described anomie as a condition of instability due to the breakdown of social and moral norms, values, and structures because of the rapid social changes accompanied by the modernization process. He argued that the collapse of moral guidance cultivated various social problems, like deviance, social unrest, unhappiness, and stress (Durkheim, 1893). Robert Merton (1938) 
modified the anomie concept in his theory of structural strain based on individual goals and American culture. Merton (1938) argued that American culture valued monetary success and instituted means in which individuals must achieve these goals. Anomie occurred when there was a discrepancy between valued goals (e.g., wealth, money, success) and legitimate means to obtain those goals (e.g., education, career, middle-class values). Merton (1938) proposed five modes of adaptation (i.e., conformity, innovation, ritualism, retreatism, rebellion) that acted as a mechanism to manage strain associated with anomie, where individuals accepted or rejected the culturally prescribed goals and institutionalized means of society (Merton, 1938; Parnaby \& Leyden, 2011). Messner and Rosenfeld (2001) published Crime and the American Dream, which expanded and partially reformulated Merton's (1938) institutional anomie theory. Messner and Rosenfeld argued that an imbalance in the institutional structure prevented social institutions (e.g., family, education, political systems, economy) from protecting individuals from the criminogenic pressures of the American Dream (Pratt \& Cullen, 2005). Despite Messner and Rosenfeld's (2001) efforts to narrow anomie to explain individual factors, it largely remained an explanation of structural-level influences.

Classic strain theorists (e.g., Cloward \& Ohlin, 1960; Cohen, 1955; Merton, 1938) focused exclusively on the failure to achieve positively valued goals and goal blockage commonly experienced by lower-class individuals in American society (Agnew, 1992; Agnew \& White, 1992). Although classic strain theories remained popular into the 1970s, they had very little impact on criminology until the work of Agnew $(1985,1989$, 1992) emerged (Swatt et al., 2007). Agnew (1985) extended classic strain theory by proposing that in addition to goal blockage, delinquency and crime occurred because of 
the inability to escape from painful or aversive circumstances. He argued that the blockage of pain-avoidance behavior caused frustration, resulting in subsequent delinquent behavior (Agnew, 1985).

Agnew (1985) outlined significant limitations of earlier strain theories. He asserted that the most damaging criticism of earlier strain theories was the research on the disjunction between aspirations and expectations. If Agnew were correct, delinquency would be greatest when aspirations were high, and expectations were low. Numerous studies tested this idea, yet most failed to find support for strain theory. Indeed, many studies concluded that delinquency was highest when both aspirations and expectations were low, and delinquency was lowest when both aspirations and expectations were high. Agnew (1985) also criticized the assertion that delinquency was restricted to the lowerclass due to limited means of achieving economic success or middle-class status. Agnew (1985) cited data suggesting that delinquency was common in the middle-class and that the relationship between class and certain types of delinquency was negligible. Finally, Agnew (1985) criticized earlier strain theories for their failure to explain decreases in delinquency as chronological age increased. More specifically, early theories could not explain why delinquents abandoned crime in late adolescence or went for long periods of time without engaging in delinquent behaviors (Agnew, 1985).

Agnew (1985) addressed these limitations by examining the relationships between aversive situations and delinquency among a sample of 2,213 boys. More specifically, the associations among aversive school and family environments, social control, subcultural deviance, and delinquency were assessed using data collected from the Youth in Transition survey. Agnew (1985) hypothesized that when controlling for social 
control and subcultural deviance, aversive school and family environments would have a direct effect on delinquency and an indirect effect on delinquency through anger. Results revealed that aversive school and family environments directly and indirectly influenced delinquency via anger. In this regard, Agnew (1985) argued that both goal blockage and inability to escape from painful or aversive circumstances were sources of strain.

Agnew (1989) examined the relationships between environmental adversity and delinquency among a sample of 1,886 boys. In particular, self-reported delinquency was assessed with longitudinal survey data that included information on negative school attitudes, parental punitiveness, and mean teacher scales. Using structural equation modeling (SEM), Agnew (1989) hypothesized that environmental adversity would foster delinquency by causing individuals to illegally escape or attack the source of adversity; angering youth to the point that they expressed their anger onto others; and decreasing social control. Results indicated that environmental adversity affected delinquency, while occasional delinquency also affected environmental adversity (Agnew, 1989).

Using results from his earlier studies $(1985,1989)$ as a base, Agnew (1992) proposed a general theory of crime that explained strain at the individual-level (See Figure 1). GST was introduced as a social-psychological approach of delinquency and crime that focused on individuals and their immediate social environment (Agnew, 1992; Agnew \& White, 1992). GST assumed that individuals were pressured into delinquency and crime via negative emotional states, particularly anger and related emotions resulting from negative relationships (Agnew, 1992). Additionally, GST outlined various forms and characteristics of strain, strain that fostered delinquency and crime, negative 
emotional states, coping strategies, and factors that influenced criminal coping (Agnew, 2006).

Types of strains. Strain was defined as an event or condition that was disliked by individuals (Agnew, 2006). Agnew (1992) outlined three major categories of strain that referenced different types of negative relationships with others, including "other individuals may (1) prevent one from achieving positively valued goals, (2) remove or threaten to remove positively valued stimuli that one possesses, or (3) present or threaten to present one with noxious or negatively valued stimuli” (p. 50).

\section{Actual or anticipated failure to achieve positively valued stimuli. Several} subtypes of strain were included in the first category of strain, namely "strain as the disjunction between (1) aspirations and expectations/actual achievements, (2) expectations and actual achievements, and (3) just/fair outcomes and actual outcomes" (Agnew, 1992, p. 56). Strain measured in terms of the disjunction between aspirations and expectations/actual achievements highlighted ideal goals as they related to monetary success and social class. Although, classic strain theory concentrated on several subtypes of strain as a failure to achieve positively valued goals, most early theorists (e.g., Cloward \& Ohlin, 1960; Cohen, 1955; Merton, 1938) investigated strain as the disjunction between aspirations and expectations/actual achievements, claiming that it was primarily responsible for delinquency and crime (Agnew, 1992).

Agnew (1992) extended classic strain theory by proposing that in addition to ideal and future goals, current goals must also be considered. Agnew and White (1992) argued that the failure to achieve positively valued goals was better assessed in terms of the disjunction between (a) expectations and actual achievements and (b) just/fair outcomes 
and actual outcomes. For example, they claimed that expectations were derived from past experiences and/or comparisons with similar others. Failure to achieve expectations contributed to feelings of anger, resentment, rage, dissatisfaction, disappointment, and unhappiness (Agnew, 1992). Furthermore, Agnew (1992) suggested that individuals expected distributive justice rules (i.e., interactions will conform to the justice principle) to be followed and had specific outcomes in mind during social interactions. Outcomes were comprised of positive and negative consequences, while inputs encompassed positive and negative contributions in a relationship. Outcomes were evaluated as just/fair or unjust/unfair based on the output/input ratio of those involved in the relationship. Unjust/unfair outcomes were associated with negative emotional states, such as anger and resentment. In this regard, individuals focused their goals and achievements on specific outcomes and compared those with similar others during social interactions to determine if outcomes were just/fair (Agnew, 1992).

Actual or anticipated removal of positively valued stimuli. The removal or threatened removal of positively valued stimuli occurred when an individual lost something they valued (lost something good) or valued stimuli were taken away and was related to one's experiences with stressful life events (Agnew, 2006; Akers, 2000). Examples of strain as the removal of positively valued stimuli included the loss of a significant other, death or serious illness of a loved one, divorce/separation of one's parents, leaving one's neighborhood, and suspension from school (Agnew, 1992; Agnew \& White, 1992). According to Agnew (1992), delinquency occurred when an individual attempted to prevent the loss of positive stimuli, retrieve the lost stimuli, obtain substitute 
stimuli, seek revenge against those responsible for the loss, and/or manage negative emotional states produced by the loss by using illicit drugs.

Actual or anticipated presentation of negatively valued stimuli. Agnew (1992)

argued that the presentation or threatened presentation of negatively valued stimuli cultivated delinquency and crime in particular situations. The presentation of negatively valued stimuli occurred when individuals were treated in an aversive or negative way by others (received something bad) (Agnew, 2006). Examples of strain as the presentation of noxious or negatively valued stimuli included child abuse and neglect, negative relations with parents and peers, verbal insults and threats, or other adverse experiences (Agnew, 1992; Agnew \& White, 1992). Individuals attempted to escape from or avoid the noxious stimuli, terminate or alleviate the noxious stimuli, seek revenge against the sources of the noxious stimuli or associated targets, and/or manage negative emotional states produced by the noxious stimuli by using illicit drugs (Agnew, 1992).

Measurement of Strains. Agnew (1992) argued that it was essential to properly measure each type of strain when testing predictions of GST. Since GST is much broader than current strain theories, measuring strain required at least three sets of measures, including those that focused on the (1) failure to achieve positively valued goals, (2) loss of positive stimuli, and (3) presentation of negative stimuli. Agnew (1992) did not provide precise measures to assess these areas; however, he offered general guidelines for the measurement of strain.

Develop a comprehensive list of negative relations. Agnew (1992) posited that researchers must pull from theory and research to identify objective strains generally expected to cause adversity since individuals vary in their perceptions of strains. When 
developing inventories of strainful events, researchers were cautioned that important group differences may exist in the types of strain or negative relations frequently encountered. In this regard, Agnew (1992) urged researchers to investigate factors that may cause one group to experience an event as stressful while others do not.

Examine the cumulative impact of negative relations. Agnew (2006) argued that delinquency and crime were especially likely when individuals encountered two or more strains in a short period of time. Individuals who encountered multiple strains at once were more likely to experience negative emotional states, taxing their ability to cope in a legal manner. Since it is common for strains to occur together, Agnew (1992) advised researchers to use a composite index of strain in all analyses or explore the interactions among the strain measures.

\section{Examine the magnitude, recency, duration, and clustering of adverse events.}

Agnew (1992) urged researchers to consider adverse events that were high in magnitude, recent, of long duration, and clustered in time. The meaning of magnitude varied based on the type of strain under investigation. In terms of goal blockage, magnitude referred to the size of gap between individual goals and reality. Specific to the loss of positive stimuli, magnitude referred to the amount lost. With respect to the presentation of noxious stimuli, magnitude referred to the degree of pain or discomfort inflicted. Agnew (1992) noted that individual perceptions of strain must be considered since there was no standard metric available for measuring magnitude.

According to Agnew (1992), recency of adverse events was an important dimension to consider as well as those of long duration (i.e., chronic stressors) or expected to persist into the future. Since strainful events clustered closely in time were 
more likely to overwhelm coping resources and have larger effects on negative outcomes, they must also be considered in the measurement of strain (Agnew, 1992).

Negative Emotional States. Each type of strain increased the possibility that individuals would experience a range of negative emotional states, such as anger, frustration, jealousy, malicious envy, depression, fear, shame, and alienation (Agnew, 1992; Agnew, 2006; Agnew \& White, 1992; Swatt et al., 2007). These negative emotional states produced pressure for corrective action to reduce or eliminate felt strain. In other words, negative emotional states prepared individuals to engage in various coping strategies to lessen negative affect produced by strain (Swatt et al., 2007). These negative emotional states also decreased the ability to legally cope and reduced the perceived costs of crime, all of which created a disposition for delinquency and crime (Agnew, 2006). Although negative emotional states involved the negative assessment of an event or condition, they were distinguished from each other based on feelings of power or potency and level of activity (Agnew, 2006).

Anger. According to Agnew (2006), anger occurred when individuals experienced unjust treatment by others. Anger was related to feelings of power and a need to react to perceived injustices. Many emotions closely associated with anger included frustration, malicious envy, and jealousy. Frustration occurred when individuals found it challenging to meet their goals and promoted feelings of unfulfilled desires. Malicious envy resulted when individuals believed they had a right to possess what others had and produced feelings of inferiority, longing, and ill will. Jealously resulted when individuals were threatened with the loss of an important relationship to a rival and involved feelings of suspicion, distrust, and fear of loss (Agnew, 2006). 
Anger and related emotions contributed to delinquency and crime for many

reasons. For example, these negative emotional states generated pressure for corrective action. More specifically, they produced a strong need to correct perceived injustices or satisfy desires. They also reduced the ability to engage in legal coping. Angry individuals were less likely to accurately evaluate situations or effectively communicate with others. Angry individuals were also more likely to attribute malicious intent to the behavior of others and were easily offended. Furthermore, angry individuals were less concerned about the costs of crime and less likely to consider the long-term consequences of their behavior. Lastly, angry individuals had a strong desire for retaliation/revenge and were more likely to believe that crime was justified. In this regard, angry individuals were more susceptible to delinquency and crime (Agnew, 2006).

Depression. Agnew (2006) contended that depression occurred when individuals experienced a disliked event or condition (e.g., death of a loved one). Depressed individuals felt powerless or unable to change the disliked state of affairs and became inactive, lethargic, and listless. Emotions closely associated with depression included anguish, despair, hopelessness, and disappointment. Like anger, depression contributed to delinquency and crime because it produced pressure for corrective action. Although depression was an unpleasant emotional state, it did not generate as much pressure as anger. Depression also decreased the ability to engage in legal coping since depressed individuals were lethargic and felt powerless to act. "Depression reduces the perceived costs of crime, as the misery experienced by depressed individuals may lead them to feel that they have little to lose by committing crime" (Agnew, 2006, p. 35). 
Fear. Fear occurred when individuals expected to experience a disliked event or condition. Fearful individuals felt powerless to stop the disliked state of affairs and possessed a strong desire to flee or hide. Emotions closely related to fear included terror, panic, and anxiety. Like anger and depression, fear increased the likelihood of delinquency and crime. Fear was less strongly associated with other-directed crimes than anger and more strongly associated with criminal efforts to flee or hide, like running away, truancy, skipping school, and drug use (Agnew, 2006).

Coping Strategies. While strains increased the possibility of delinquency and crime, most individuals coped with their strains and negative emotional states in noncriminal ways (Agnew, 2006). Agnew (1992) proposed a typology of three broad adaptations to strain, each acting as a mechanism to reduce or eliminate negative emotional states produced by strain; these included cognitive, behavioral, and emotional coping strategies. Individuals could be classified by their overall coping style, which referred to the various types of coping they tended to use and how often they used them. Others, however, could employ more than one coping strategy. Indeed, some could frequently use a broad range of coping strategies, while others concentrated on only one or a few types. Still, others reported that they made little or no effort to cope with their strains (Agnew, 2006).

Cognitive coping. Individuals relied on cognitive coping strategies to reinterpret objective strains in ways that minimized their subjective adversity (Agnew, 1992; Agnew, 2006; Swatt et al., 2007). According to Agnew (1992), cognitive coping strategies assumed three forms. The first adaptation was for individuals to ignore or minimize the importance of adversity. The subjective impact of objective strain was 
based on the extent to which the strain was associated with primary goals, values, and identities. In this regard, individuals could claim that certain goals, values, or identity were unimportant in an absolute and/or relative sense. For example, an individual with poor academic grades could cope with the strain by rationalizing that school was unimportant to them or that school was less important than leisure activities (Agnew, 1992).

The second adaptation of cognitive coping was for individuals to deny the presence of adversity by maximizing positive outcomes and/or minimizing negative outcomes. Agnew (1992) suggested that this type of coping was achieved by either lowering their standards used to assess outcomes or distorting their estimate of outcomes. For instance, an individual with poor academic grades could cope with the strain by lowering their standards to accommodate a D+ average. They could also exaggerate their actual and expected levels of goal achievement by telling others they were doing well in school, even though they were doing poorly. Finally, individuals could minimize negative outcomes by claiming that their academic grades were not that bad (Agnew, 1992).

The third and final adaptation of cognitive coping was for individuals to accept responsibility for adversity. By convincing themselves that they deserved the adversity they experienced, individuals lessened the subjective adversity of objective strain. For example, an individual with poor academic grades could cope with the strain by accepting the fact that they did not take the necessary time to study for exams or put forth only minimal effort on their homework assignments (Agnew, 1992). 
Behavioral coping. Behavioral coping strategies consisted of employing delinquent or conventional behaviors to minimize or eliminate adversity or extract revenge upon the stressor (Agnew, 1992; Swatt et al., 2007). Individuals relied on behaviors to protect or retrieve things they valued, terminate or escape from aversive treatment, or achieve their goals (Agnew, 2006). For example, an individual who was sexually harassed in the work setting could transfer to another department within the organization or fail to show up to work to avoid victimization. Additionally, the individual could engage in vengeful behaviors to minimize positive outcomes, increase negative outcomes, and/or increase inputs for the sources of the strain or associated targets (Agnew, 1992).

Emotional coping. Emotional coping occurred when individuals acted directly upon emotions to alleviate negative emotional states caused by adversity, rather than cognitively reinterpret or behaviorally modify the strains that produced the emotions. Emotional coping strategies could be criminal or non-criminal in nature (Agnew, 1992; Agnew, 2006; Swatt et al., 2007). Emotional coping also involved efforts to seek revenge against the source of strain or associated targets. Strains frequently produced a strong need for revenge that was distinct from the desire to reduce or escape from the strains. Recent data suggest that vengeful behavior often makes one feel better (Agnew, 2006). Examples of emotional coping strategies included illicit drug use, physical exercise, meditation, deep breathing techniques, biofeedback, progressive muscle relaxation, and expression work (i.e., behavioral manipulation of expressive gestures via playacting) (Agnew, 1992; Agnew, 2006; Swatt et al., 2007). Agnew (1992) suggested that emotional coping was more likely to occur if cognitive and behavioral coping 
strategies were unavailable or ineffective. Individuals could utilize multiple coping strategies simultaneously (Agnew, 1992; Swatt et al., 2007).

Factors that Influence Criminal Coping. According to Agnew (2006), whether individuals reacted to strains with delinquency and crime depended on the types of strains experienced as well as the characteristics of individuals and their environments.

Particular individual and environmental characteristics reduced the likelihood of legal behavioral coping and undermined the effectiveness of emotional and cognitive coping. Factors that increased the likelihood of criminal coping included poor coping skills and resources and low levels of conventional social support. These factors decreased the ability to participate in legal coping, reduced the costs of crime, and increased the disposition for delinquency and crime. Furthermore, these factors increased the possibility of criminal coping by affecting the perception of and sensitivity to strains. More specifically, these factors influenced the subjective perception of objective strains, especially the perceived magnitude and injustice of objective strains (Agnew, 2006).

Poor coping skills and resources. Some individuals lacked the necessary skills and resources to legally cope with strains or possessed certain coping skills and resources that promoted criminal coping. For instance, individuals with poor problem-solving and social skills were less likely to enact prosocial responses to strains. Various sociodemographic characteristics also affected the ability to cope with strains in a legal manner, including age, gender, race/ethnicity, and socioeconomic status (SES). Individuals who possessed resources (e.g., money, education, good jobs) were better equipped than lower SES individuals to cope in a legal manner (Agnew, 2006). 
In addition to individual skills and sociodemographic characteristics, individuals who possessed low constraint and negative emotionality were less able to cope with strains in a legal manner. Individuals who possessed these traits were impulsive and lacked awareness of and concern for the costs of crime. In particular, these individuals gave little thought to the consequences of their behavior and cared little about social norms or rules. Given their attraction to risky activities and aggressive interactional style, these individuals had a greater disposition for delinquency and crime. Finally, due to their greater sensitivity to strains and tendency to blame their problems on others, these individuals perceived objective strains as high in magnitude and unjust, both of which were conductive to criminal coping (Agnew, 2006).

Low self-efficacy also contributed to criminal coping. According to Agnew (2006), self-efficacy referred to one's belief that they possessed the ability to cope in a legal manner. Individuals with high self-efficacy believed they could successfully manage problems they experienced in a legal manner. Those with high self-efficacy were more likely to rely on legal behavioral coping strategies. Individuals with low selfefficacy believed there was little they could do to legally respond to their strains, so they were more likely to participate in criminal coping (Agnew, 2006).

Agnew (2006) argued that the inability to respond to strains in a legal manner did not guarantee criminal coping would result. Indeed, individuals must also possess the skills and resources necessary for criminal coping. Other skills and resources that promoted the commission of violent crimes included physical size and strength, fighting ability, and the possession of an aggressive demeanor. A more general resource that facilitated criminal coping was the level of criminal self-efficacy. Criminal self-efficacy 
referred to the degree to which individuals believed they could successfully respond to their strains with criminal coping. Individuals who possessed high criminal self-efficacy frequently considered themselves tough, street-smart, and adept at criminal coping (Agnew, 2006).

Low levels of conventional social support. Agnew (2006) noted that individuals frequently received assistance or support from conventional others (e.g., family members, friends, teachers, neighborhood residents, religious figures, government agencies) when coping with their strains. Conventional social support assumed many forms. For example, others offered emotional support; provided information or advice on how to manage strains; directly assisted in coping efforts; and coped for someone. Individuals varied in the extent to which they received conventional social support. Those who received less support had a higher likelihood of engaging in criminal coping (Agnew, 2006).

Figure 1. General Strain Theory

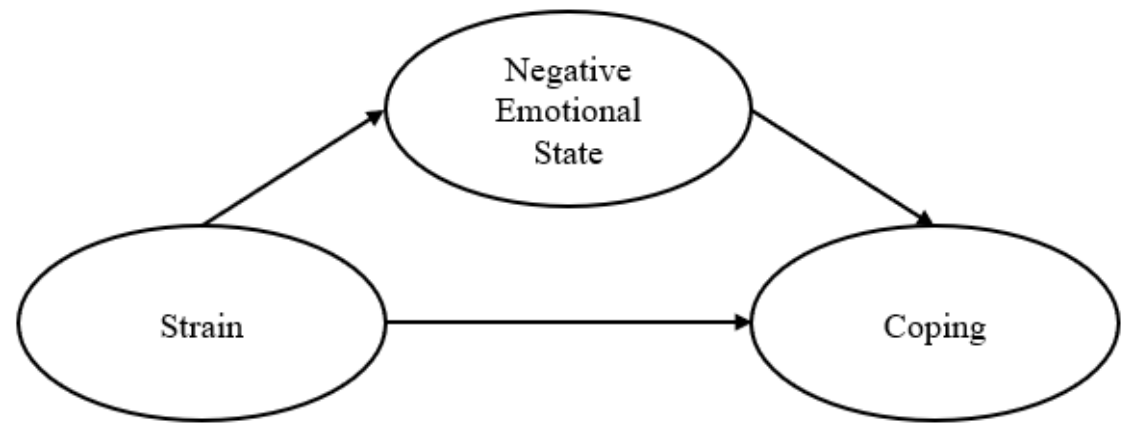

\section{Empirical Evidence for General Strain Theory}

Adolescent and college student samples. Much of the research that tested predictions of GST concentrated on establishing a relationship to deviance among adolescent school samples or samples of college students, with many studies offering support for GST. The types of deviance typically examined in these studies include 
property crime, violent offenses (e.g., physical and sexual assault, robbery, possessing a weapon), and substance use.

Violent and non-violent offenses. Violent and non-violent offenses are frequently cited as dependent measures among adolescent and college student samples in existing GST literature. For example, a study by Hoffman and Miller (1998) tested the effects of negative life events on conventional attachment and peer delinquency among adolescents between 11 and 17 years of age. The study directly examined the coping strategies hypotheses outlined in GST by stratifying models based on self-efficacy, self-esteem, and peer delinquency using three years of data collected from the Family Health Study (FHS) (1993-1995). Several measures were constructed to test the effects of negative life events on conventional attachment and peer delinquency. Negative life events as a form of strain assessed participant experiences with family-related incidents over the past 12 months. Peer delinquency examined the degree to which participants engaged in various self-reported property (e.g., shoplifting, damaging property, theft) and violent (e.g., gang fight, carrying a weapon, attacking someone) offenses. Hoffman and Miller (1998) used SEM to test the longitudinal influences of negative life events on peer delinquency. Results offered support for only one of four hypotheses: negative life events significantly increased peer delinquency when controlling for exogeneous factors (i.e., age, family income), several complex associations among strain, conventional attachments, and delinquent behavior (Hoffman \& Miller, 1998).

Aseltine, Gore, and Gordon (2000) also investigated violent and non-violent offenses among high school students in Boston, Massachusetts. More specifically, the study explored the connections among stressful life events, strained social relationships, 
anger, anxiety, and deviant behavior using longitudinal data from a prospective study of stress, mental health, and social adaptation. Multiple measures were constructed to test the associations. Life stress as a form of strain evaluated participant experiences with various negative life events over the past 12 months. Family conflict as a form of strain measured the frequency of participant-parent arguments and the extent to which family members fought, argued, or disagreed with each other. Peer conflict as a form of strain assessed the degree to which participants experienced conflict with peers. Negative affect measured participant levels of anger and anxiety. Delinquency examined aggressive (e.g., damaging property, carrying a hidden weapon, getting into physical fights) and non-aggressive (e.g., stealing or trying to steal things, running away from home, driving while impaired) behaviors and the frequency of marijuana use among participants. Like Hoffman and Miller (1998), Aseltine et al. (2000) used SEM to investigate the longitudinal impact of stressful life events, strained social relationships, anger, and anxiety on deviant behavior. Results suggested that negative life events and family conflict were significantly and positively associated with deviant behavior. Results also offered support for the role of both anger and anxiety in mediating the effect of negative life events and strained social relationships on some forms of delinquency; however, the effects were only significant for aggressive behaviors. No measures of strain or negative affect were significantly associated with marijuana use (Aseltine et al., 2000).

In addition to negative life events, other studies informed by predictions of GST have also demonstrated a link between victimization and violent and non-violent offenses. For instance, Hay and Evans (2006) studied the impact of violent victimization 
on later involvement in delinquency among children and adolescents between seven and 16 years of age using longitudinal data collected from the National Survey of Children. Several measures were constructed to test the relationship. Violent victimization as a form of strain evaluated participant experiences with victimization in their neighborhood. Anger measured participant experiences with angry emotions. Multiple delinquency measures assessed a range of offense types, including violent, property, substance use, public order, and status offenses among participants. Regression models were generated to study the effects of violent victimization, anger, conditioning factors, and interactions between violent victimization and conditioning factors on delinquency. Results indicated that violent victimization significantly predicted later involvement in delinquency, even when controlling for prior involvement in delinquency. Additionally, the influences of violent victimization on later involvement in delinquency were explained in part by the role of anger (Hay \& Evans, 2006).

Additionally, Sigfusdottir, Kristjansson, and Agnew (2012) tested the comparative differences in violent and non-violent offending among high school students in local secondary schools across five cities in Europe using cross-sectional data collected from the Youth in Europe Survey. Multiple measures were constructed to test the effects of key strains known to cultivate delinquency. Comparable to Hay and Evans (2006), physical victimization as a form of strain examined participant experiences with physical violence over the past 12 months. Economic deprivation as a form of strain evaluated family income. School strain as a form of strain measured participant attitudes concerning their school experiences. Family conflict as a form of strain assessed tension among families. Peer rejection as a form of strain examined participant experiences with 
the loss of a significant relationship. Violent crime evaluated how often participants had assaulted, threatened, and used physical violence to rob, steal, and force someone to have sexual relations with them. Property crime measured how often participants had stolen something, broken into a building or car to steal, and vandalized things that did not belong to them. Regression models were estimated to test the influences of physical victimization, economic deprivation, school strain, family conflict, and peer rejection on violent and property crimes for each city. Results offered strong support for four of five strains examined. Physical victimization, school strain, family conflict, and peer rejection were all significantly related to violent and property delinquency in the five cities, even when controlling for various sociodemographic characteristics (Sigfusdottir et al., 2012).

Along with victimization, a study by Moon, Hays, and Blurton (2009) investigated the influences of other key strains, negative emotions, and conditioning factors on violent and non-violent offenses among undergraduate students at a state university in the United States. Several measures were constructed to test the associations. Goal blockage as a form of strain assessed whether participants were successful at achieving socially desirable goals over the past five years. Family conflict examined the degree of experience regarding arguments and tension among family members over the past five years. Parental punishment evaluated the frequency of parental emotional and physical punishment of participants. Teachers' emotional punishment measured the frequency of teachers' emotional punishment of participants. Gender discrimination assessed participant experiences of gender discrimination. Race discrimination examined participant experiences of racial discrimination. Criminal 
victimization evaluated participants' and their family's victimization experiences. Negative community environment measured various types of problems in participant neighborhoods. Negative emotion assessed whether participants felt uncontrollable outbursts of temper, urges to harm someone, or urges to break things over the past five years. Deviance examined how often participants engaged in various types of deviant behaviors over the past five years and the distinctive effect of strains on violent and nonviolent offenses. Regression models were generated to investigate the impact of eight key strains, negative emotion, conditioning factors, and interactions between strains and conditioning factors on deviant behaviors. Results demonstrated that teachers' emotional punishment and race discrimination were significantly associated with deviance. Results also revealed that anger did not have a significant mediating effect linking strains to deviance (Moon et al., 2009).

Police officer samples. Research testing predictions of GST have also occurred in various organizational settings, such as government entities, non-profit agencies, and private businesses (Simpson \& Weisburd, 2009). More recently, empirical studies have examined the utility of GST in explaining strain among police officers. The outcomes of strain typically examined in these studies include alcohol use, physical aggression, organizational commitment, burnout, and turnover intention.

Alcohol use. Alcohol use is cited as a dependent measure among police officer samples in existing GST literature. For example, Swatt et al. (2007) explored the utility of GST in explaining drinking prevalence and problematic alcohol consumption among police officers using data collected from the Police Stress and Domestic Violence in Police Families in Baltimore, Maryland Study (1997-1999). Multiple measures were 
constructed to test the relationships. The strain measure assessed participant experiences with dangerous work-related events. Negative affect examined the degree of angry/irritable and anxious/depressive behaviors among participants. Problematic alcohol consumption distinguished drinkers from non-drinkers and identified problematic drinking behaviors among participants. Regression models were estimated to explore the effects of subjective work-related strain, anger/irritability, and anxiety/depression on problematic alcohol consumption. Results suggested that work-related strain affected both anger/irritability and anxiety/depression. Results also offered support for the role of anxiety/depression in mediating the effect of work-related strain on problematic alcohol consumption (Swatt et al., 2007).

Yun and Lee (2015) also studied the generality of GST in explaining hazardous alcohol consumption among Korean police officers. More specifically, the study tested the influences of operational and organizational strains on problematic alcohol use and the mediating effects of anger, depression, and anxiety independently on the strainalcohol consumption relationship using data collected from the Daejun Metropolitan Police Agency (DMPA). Several measures were constructed to test the effects of key occupational strains known to cultivate alcohol use among police officers. Operational strain evaluated how often participants experienced traumatic or otherwise dangerous events and how stressful those strains were over the past 12 months. Organizational strain measured how often participants experienced stressful events stemming from the bureaucratic characteristics of the police organization and how stressful those strains were over the past 12 months. Negative affect assessed participant levels of anger, depression, and anxiety. Hazardous alcohol consumption distinguished drinkers from 
non-drinkers and identified hazardous drinking behaviors among participants.

Regression models were generated to study the influences of strain, negative affect, and conditioning factors on hazardous alcohol consumption. Results indicated that anger, depression, and anxiety were all significantly related to organizational strain. Additionally, results demonstrated that no measure of negative affect mediated the relationship between operational strain and the drink/no drink alcohol consumption outcome. Alternatively, depression mediated the relationship between organizational strain and the hazardous alcohol consumption outcome (Yun \& Lee, 2015).

Physical aggression. Physical aggression is also cited as a dependent measure among police officer samples in existing GST literature. For example, Gibson et al. (2001) investigated the utility of GST in explaining domestic violence among male police officers using data collected from the Police Stress and Domestic Violence in Police Families in Baltimore, Maryland Study (1997-1999). Multiple measures were constructed to test the associations. Job dissatisfaction as a form of strain examined participant levels of satisfaction with their job. Negative work-related events as a form of strain evaluated the degree of exposure to negative work-related events among participants. Negative affect measured participant levels of depression and anger in response to occupational strain. Domestic violence assessed whether participants ever lost control and physically assaulted their spouse/significant other, child(ren), and pet(s). Regression models were estimated to investigate the impact of occupational strain, depression, and anger on domestic violence. Results revealed that occupational strain had an indirect effect on domestic violence through depression and anger; however, occupational strain and domestic violence did not have a direct relationship. Overall, 
results offered support for GST as a viable framework in explaining domestic violence among police officers (Gibson et al., 2001).

A study by Kurtz et al. (2015) also explored physical aggression among police officers. More specifically, the study tested the influences of prior strains on workrelated critical incident strain, psychological-physiological stress responses, and officeron-officer aggression using data collected from the Police Stress and Domestic Violence in Police Families in Baltimore, Maryland Study (1997-1999). Several measures were constructed to test the relationships. Child maltreatment as a form of strain examined history of child abuse among participants. Interparental violence as a form of strain evaluated history of interparental domestic violence among participants. Work-related critical incident strain measured participant experiences with traumatic work-related events. Psychological-physiological stress assessed participant experiences with various psychological and physiological symptoms of stress. Officer-on-officer aggression examined a serious form of maladaptive behavior among participants. Regression models were generated to explore the effects of prior child maltreatment and interparental violence on work-related critical incident strain, psychological-physiological stress, and officer-on-officer aggression. Results suggested that participants with prior child maltreatment and interparental violence had higher work-related critical incident strain. Additionally, prior child maltreatment, interparental violence, and work-related critical incident strain were related to increased psychological-physiological stress. Results indicated that prior child maltreatment and work-related critical incident strain increased the odds of officer-on-officer aggression (Kurtz et al., 2015). 


\section{Organizational commitment, burnout, and turnover intention. Organizational}

commitment, burnout, and turnover intention are also cited as dependent measures among police officer samples in existing GST literature. For example, Moon and Jonson (2012) investigated organizational commitment among police officers using data collected from police personnel in multiple law enforcement agencies located throughout Northern Kentucky. Multiple measures were constructed to test the effects of various occupational strains on organizational commitment among police officers. Failure to achieve positively valued goals as a form of strain evaluated participant attitudes about whether they would still pursue a career in law enforcement knowing what they know now. Removal of positively valued stimuli as a form of strain measured the degree to which participants' job limited positive time with their family. Presentation of noxious stimuli as a form of strain assessed stressful encounters and work/role responsibilities among participants. Stressful encounters examined various physical encounters, emotional situations, and psychological stressors among participants. Work/role responsibilities evaluated role conflict, ambiguity, and problems encountered while on-duty among participants. Negative affect measured participant negative emotional states manifested in the home setting. Organizational commitment assessed participant levels of loyalty, pride, and intentions to leave or help their police agency. Regression models were estimated to identify significant predictors of organizational commitment. Results demonstrated that all strain measures directly influenced organizational commitment when negative affect was included in the analyses. Both failure to achieve positively valued goals and removal of positively valued stimuli were negatively associated with organizational commitment. Alternatively, both presentation of noxious stimuli measures 
were positively related to organizational commitment. In other words, participants who experienced more stressful encounters and had more clearly defined and understood work/role responsibilities were more committed to their police agency. Failure to achieve positively valued goals and removal of positively valued stimuli significantly predicted greater negative affect; however, negative affect did not mediate the relationship for any strain measure and organizational commitment (Moon \& Jonson, 2012).

Bishopp et al. (2018) utilized GST to explore the differential influences of environmental and organizational strain on anger, depression, and burnout among police officers from three police departments in Texas using data collected from the Police Work Experience Survey (PWES). Several measures were constructed to test the associations. Environmental strain examined participant experiences with serious streetrelated incidents over the past six months. Organizational strain evaluated how much stress certain organizational strains caused for participants over the past six months. Negative affect measured participant levels of depression, anger, and burnout. Regression models were generated to explore the influences of environmental and organizational strain on anger, depression, and burnout. Results revealed that organizational strain significantly impacted anger among all three police departments and did not differ greatly, suggesting that participants in urban departments experienced similar organizational stressors regardless of geographic location. Additionally, the influence of organizational stress on depression had slightly more variation but was still a significant correlate. Results also indicated that organizational strain had the greatest 
impact on burnout among all three police departments. Environmental strain was the only significant correlate for anger (Bishopp et al., 2018).

Shim et al. (2015) studied the mediating effects of negative emotions on the association between occupational strain and turnover intention among Korean police officers using data collected from the Korean Social Science Data Archive (KSSDA) as part of a Survey of Police Officers' Perception on Improving Criminal Investigation (2007). Multiple measures were constructed to test the relationships. The gap between expectations and actual outcomes (i.e., goal blockage) as a form of strain assessed participant income and promotion opportunities. Removal of positively valued stimuli as a form of strain examined participant perceptions of economic loss derived from spending their money on investigative tasks. Presentation of noxious stimuli as a form of strain evaluated participant experiences with being injured while on-duty. Negative affect measured participant levels of frustration, depression, and anxiety. Turnover intention assessed whether participants thought about changing their job, felt regret about accepting their job, and assumed their job as lifework. Regression models were estimated to study the impact of occupational strain and negative affect on turnover intention. Results suggested that goal blockage was the only strain measure significantly associated with turnover intention. Results also offered support for the role of both frustration and depression in mediating the effect of occupational strain on turnover intention (Shim et al., 2015).

Limitations of existing empirical evidence. Research on adolescent, college student, and police officer samples suggest that GST can explain a range of maladaptive behavior adopted by individuals to cope with felt strain. For example, GST has been 
utilized to examine violent and non-violent offenses (Aseltine et al., 2000; Hay \& Evans, 2006; Hoffman \& Miller, 1998; Moon et al., 2009; Sigfusdottir et al., 2012), alcohol use (Swatt et al., 2007; Yun \& Lee, 2015), physical aggression (Gibson et al., 2001; Kurtz et al., 2015), organizational commitment (Moon \& Jonson, 2012), occupational burnout (Bishopp et al., 2018), and turnover intention (Shim et al., 2015). Although the results obtained in these studies offered support for GST, many failed to measure strain properly. Indeed, many researchers assessed strain with non-validated measures, limited items, or simplistic measures that did not consider various characteristics or dimensions of strain. For example, all studies utilized data that were not initially collected to examine GST principles. In this regard, researchers had to construct measures derived from a small number of items (Aseltine et al., 2000; Kurtz et al., 2015; Moon et al., 2009; Moon \& Jonson, 2012; Shim et al., 2015; Sigfusdottir et al., 2012) or items with lower levels of reliability (Hoffman \& Miller, 1998) than preferred. Likewise, multiple studies (Bishopp et al., 2018; Gibson et al., 2001; Hay \& Evans, 2006; Hoffman \& Miller, 1998; Kurtz et al., 2015; Swatt et al., 2007; Yun \& Lee, 2015) failed to consider the three primary categories of strain due to the nature of the data. Including few items in a measure sufficiently limits the measurement of the theoretical construct under investigation, and the absence of extensively validated measures allows for the possibility of other factors not considered in the analyses to account for the observed relationships.

While prior research demonstrated that various strain indices significantly influenced the dependent measures, all but two studies (Aseltine et al., 2000; Hoffman \& Miller, 1998) relied on traditional regression analyses to test hypotheses. SEM is an analytic strategy that addresses several limitations observed in prior studies by allowing 
for the correction of attenuation caused by measurement error of the indicators and having higher flexibility of simultaneously modeling relationships among various independent and dependent latent measures (Hoffman \& Miller, 1998; Manzoni \& Eisner, 2006).

\section{The Present Study}

GST expanded on earlier strain theories by explaining additional forms and characteristics of strain, negative emotional states, and coping strategies that cultivate delinquency and crime (Agnew, 2006). Indeed, GST has been applied by researchers to examine how certain strains impact delinquency and crime and explain the mediating effects of negative affect on numerous dependent measures. Although GST was originally developed to explain delinquency among youth, it has been utilized to explore other types of behavior, like alcohol use (Swatt et al., 2007; Yun \& Lee, 2015), physical aggression (Gibson et al., 2001; Kurtz et al., 2015), organizational commitment (Moon \& Jonson, 2012), occupational burnout (Bishopp et al., 2018), and turnover intention (Shim et al., 2015). Although prior research offered support for GST, many studies failed to measure strain properly. In fact, several researchers assessed strain with less than optimal psychometric properties (Hoffman \& Miller, 1998), limited items (Aseltine et al., 2000; Kurtz et al., 2015; Moon et al., 2009; Moon \& Jonson, 2012; Shim et al., 2015; Sigfusdottir et al., 2012), or simplistic measures that did not consider various aspects of strain (Bishopp et al., 2018; Gibson et al., 2001; Hay \& Evans, 2006; Hoffman \& Miller, 1998; Kurtz et al., 2015; Swatt et al., 2007; Yun \& Lee, 2015). Additionally, all but two studies (Aseltine et al., 2000; Hoffman \& Miller, 1998) relied on traditional regression analyses to test hypotheses. 
The current study seeks to overcome limitations of prior empirical studies that tested predictions of GST. The study evaluates the generalizability of GST by applying its propositions to a sample of police officers using a validated police strain measure. Unlike strain measures employed in prior GST studies with police samples (Bishopp et al., 2018; Gibson et al., 2001; Kurtz et al., 2015; Moon \& Jonson, 2012; Shim et al., 2015; Swatt et al., 2007; Yun \& Lee, 2015), the measure included in the current study contains an extensive list of strains that captures multiple types of strain unique to the policing context. The current research contributes to the empirical development of GST by testing the framework using rigorous statistical methods and new sample data. More specifically, the investigation examines the mediating effect of depression on the relationship between strain and substance use as a form of coping among police officers. Informed by the tenets of GST, the study examines multiple research hypotheses. Figure 2 displays a graphical representations of the expected direct and indirect relationships among strain, depression, and substance use as a form of coping. It is expected that strain will have a direct effect on substance use as a form of coping or that its effects will be mediated by depression.

Figure 2. Direct and Indirect Effects Theoretical Model

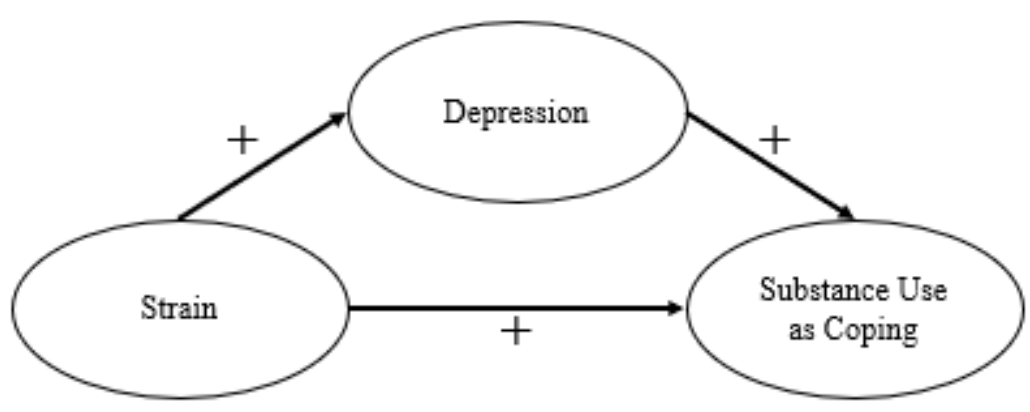




\section{CHAPTER III}

METHOD

\section{Data and Participants}

The data for the current study were initially collected using survey research to investigate stress and burnout responses among police officers and the role that coping strategies, resilience, and critical thinking played in the development, maintenance, and severity of stress symptoms exhibited. Survey research is defined as a data collection method that applies a standard instrument in a systematic way to gather measures from a large number of units (Maxfield \& Babbie, 2015).

The researcher collaborated with a retired police sergeant to secure approval from the police chief to distribute questionnaire packets to police officers employed at the department. Once permission was granted, the researcher submitted an online application to a University Institutional Review Board. When the application was approved, the retired police sergeant attended day, mid-watch, and late-watch roll calls; division and unit meetings; and trainings at the police training academy to recruit police officers for the study between January and February 2016.

Prior to distributing questionnaire packets, informed consent was obtained from police officers who volunteered to participate in the study. Informed consent is a process in which individuals agree to participate in research only after they are informed of the 
study's purpose, goals, procedures, and potential risks and benefits (Maxfield \& Babbie, 2015). Informed consent forms were distributed to participants. The informed consent form explained the study's purpose, target population, participant requirements, rights to withdraw from the study, method for maintaining confidentiality and protecting the rights and welfare of participants, and potential risks and benefits of participation. The purpose of the study was to investigate stress and burnout responses among police officers and the role that coping strategies, resilience, and critical thinking played in the development, maintenance, and severity of stress symptoms exhibited. The target population was described as uniformed and non-uniformed police officers who ranged in rank from recruit to major and were assigned to various units and positions within the department. No exclusion criteria were listed. Participant requirements included completion of an informed consent form, demographic questionnaire, and six surveys, including the High Stress Inventory (HSI), Spina Officer Scale (SOS), COPE Inventory (COPE), Ross Resilience Scale (RRS), Consolidating Assessment of Critical Thinking Under Stress (CACTUS), and Burnout Clinical Subtype Questionnaire (BCSQ). Participants were informed of their right to withdraw from the study at any time and for any reason, including no reason, without penalty. To maintain confidentiality and protect the rights and welfare of participants, a series of steps were described that prevented identifying information from being linked to participant data (e.g., name only included in informed consent form; name kept separate from individual responses; individual responses not shared with members of the department; data analyzed in group format). Participants were also given permission to skip parts of the demographic questionnaire if they believed answering certain questions would identify them. Participants were advised that 
any risks of participation were judged to be minimal, if any. For example, although no serious risks of participation were known, participants were cautioned that they could experience discomfort in response to questions about sensitive topics (e.g., substance use, mental health). Lastly, participants were informed that their involvement in the study would indirectly benefit researchers and practitioners by providing information that could assist them in developing effective stress prevention, intervention, and training programs tailored to police officers.

After informed consent forms were signed and collected, questionnaire packets in paper and pencil format were distributed to participants in a group setting at various police facilities (e.g., headquarters, divisions, training center). Time to complete the questionnaire packet took approximately one-hour. As questionnaire packets were returned, participants were provided with contact information and encouraged to contact the research team with any questions or concerns.

Out of approximately 400 police officers invited to participate in the study, 221 questionnaire packets were completed. The response rate was 55\%. Participant data were hand-entered into SPSS. The electronic database contained no identifying information and was secured via password protection. All collected hard copies of the informed consent forms, demographic questionnaires, and surveys were stored in a locked filing cabinet in the psychology department on a university campus.

\section{Measures}

The measures used in the current study were adapted from the SOS, HSI, and COPE. The three surveys were originally administered to a sample of police officers to examine the impact of unique police stressors and coping strategies on the development, 
maintenance, and severity of stress symptoms exhibited. Several items were selected from the surveys to assess the theoretical concepts of strain, negative affect, and coping described in general strain theory (GST). More specifically, measures were constructed to examine strain (i.e., financial problems, time away from family, media scrutiny), depression, and substance use as a form of coping among police officers. Since the surveys were already administered to the sample, the newly generated measures were not pre-tested to determine if they accurately assessed the theoretical concepts of interest.

Independent and dependent measures. Theory describes relationships that are logically expected among measures, which generally implies the notion of causation. In cause and effect terms, an independent measure is the cause, while the dependent measure is the effect (Maxfield \& Babbie, 2015). Informed by the predictions of GST, the independent measures for the current study was strain (i.e., financial problems, time away from family, media scrutiny) and depression; the dependent measure for the current study was substance use as a form of coping. All independent and dependent measures met the criteria for ordinal levels of measurement.

Strain. Agnew (2006) described strain as an event or condition that was disliked by individuals. Agnew (1992) outlined three primary types of strain that referenced different kinds of negative relationships with others, including the actual or anticipated failure to achieve positively valued stimuli, actual or anticipated removal of positively valued stimuli, and actual or anticipated presentation of negatively valued stimuli. The actual or anticipated failure to achieve positively valued stimuli resulted when there was a disjunction between aspirations and expectations, expectations and achievements, and just/fair outcomes and actual outcomes (Agnew, 1992). The actual or anticipated 
removal of positively valued stimuli occurred when individuals lost something they valued (lost something good). The actual or anticipated presentation of negatively valued stimuli resulted when individuals were treated in an aversive or negative way by others (received something bad) (Agnew, 2006). For the current study, a strain measure comprised of three summative scales was constructed from the SOS to examine the three main categories of strain (See Table 1). The strain measure was scaled directionally, with higher scores suggesting greater levels of strain experienced among participants.

Financial problems. Strain in the form of actual or anticipated failure to achieve positively valued stimuli was measured by examining the gap between expectations and actual outcomes concerning police officers' financial obligations. Five items comprised the financial problems summative scale $(\alpha=0.84)$ (See Table 1). Each item required participants to indicate how stressful each statement was on a four-point Likert-scale. The response categories were coded such that $1=$ Not stressful at all, $2=$ Mildly stressful, $3=$ Moderately stressful, and $4=$ Extremely stressful. Higher scores indicated greater financial problems experienced among participants.

Time away from family. Strain in the form of actual or anticipated removal of positively valued stimuli was measured by exploring the degree to which police officers' job limited positive family time. Four items comprised the time away from family summative scale $(\alpha=0.87)$ (See Table 1$)$. Each item required participants to indicate how stressful each statement was on a four-point Likert-scale. The response categories were coded such that $1=$ Not stressful at all, $2=$ Mildly stressful, $3=$ Moderately stressful, and $4=$ Extremely stressful. Higher scores indicated greater time spent away from family due to work obligations among participants. 
Media scrutiny. Strain in the form of actual or anticipated presentation of negatively valued stimuli was measured by assessing the extent to which police officers experienced media scrutiny. Five items comprised the media scrutiny summative scale ( $\alpha$ $=0.87)($ See Table 1$)$. Each item required participants to indicate how stressful each statement was on a four-point Likert-scale. The response categories were coded such that $1=$ Not stressful at all, $2=$ Mildly stressful, $3=$ Moderately stressful, and $4=$ Extremely stressful. Higher scores indicated greater media scrutiny experienced among participants. The SOS is a self-report measure that assesses the perception of work and nonwork stress factors relative to law enforcement personnel. The measure is based on various internal and external stressors. Internal stressors represent events that evolve within the police department, while external stressors represent events that evolve outside the police department. In addition to unique police stressors, the SOS measures coping abilities and support systems, stress related to the organization and climate of the police department, and daily job responsibilities. The SOS is comprised of 108 items divided into eight subscales, including Administration, Personal Matters, Legal System, Image, Time, Judgment, Public Relations, and Adjunct Services (Spina, 2005; Wilson, 2015). The SOS has previously been administered to police officers employed with the Miami Police Department, Miami Beach Police Department (Spina, 2005), and Louisville Metro Police Department (Wilson, 2015). 
Table 1.

Strain Measure

\begin{tabular}{|c|c|c|c|}
\hline Type of Strain & $\begin{array}{l}\text { Measurement } \\
\text { of Strain }\end{array}$ & Item Description & $\begin{array}{c}\text { Cronbach's } \\
\text { Alpha }\end{array}$ \\
\hline \multirow{5}{*}{$\begin{array}{c}\text { Actual or } \\
\text { Anticipated } \\
\text { Failure to } \\
\text { Achieve } \\
\text { Positively } \\
\text { Valued Stimuli }\end{array}$} & \multirow{5}{*}{$\begin{array}{l}\text { Financial } \\
\text { Problems }\end{array}$} & Being contacted by financial agencies seeking payment. & \multirow{5}{*}{0.84} \\
\hline & & $\begin{array}{l}\text { Having financial responsibilities I find difficult to meet } \\
\text { (e.g.. child support, debt.. etc.). }\end{array}$ & \\
\hline & & $\begin{array}{l}\text { Not being able to qualify for a loan because my salary is } \\
\text { too low. }\end{array}$ & \\
\hline & & $\begin{array}{l}\text { Not being able to retire because I do not make enough } \\
\text { money. }\end{array}$ & \\
\hline & & $\begin{array}{l}\text { Having to work off duty to help support my financial } \\
\text { means. }\end{array}$ & \\
\hline \multirow{4}{*}{$\begin{array}{c}\text { Actual or } \\
\text { Anticipated } \\
\text { Removal of } \\
\text { Positively } \\
\text { Valued Stimuli }\end{array}$} & \multirow{4}{*}{$\begin{array}{l}\text { Time Away } \\
\text { from Family }\end{array}$} & $\begin{array}{l}\text { Being informed all days off will be cancelled because I } \\
\text { have to work a special event. }\end{array}$ & \multirow{4}{*}{0.87} \\
\hline & & $\begin{array}{l}\text { Missing special events in my family because I do not } \\
\text { have enough seniority to request off. }\end{array}$ & \\
\hline & & $\begin{array}{l}\text { Having to work during the holidays and unable to spend } \\
\text { time with my family. }\end{array}$ & \\
\hline & & $\begin{array}{l}\text { Not being able to spend quality time with my family } \\
\text { because I have to work. }\end{array}$ & \\
\hline \multirow{5}{*}{$\begin{array}{c}\text { Actual or } \\
\text { Anticipated } \\
\text { Presentation of } \\
\text { Negatively } \\
\text { Valued Stimuli }\end{array}$} & \multirow{5}{*}{$\begin{array}{l}\text { Media } \\
\text { Scrutiny }\end{array}$} & Being misquoted in a newspaper article. & \multirow{5}{*}{0.87} \\
\hline & & $\begin{array}{l}\text { Reading a news story reporting my use of force } \\
\text { incidents. }\end{array}$ & \\
\hline & & $\begin{array}{l}\text { The media being biased when reporting a case which I } \\
\text { was involved. }\end{array}$ & \\
\hline & & $\begin{array}{l}\text { Having my internal affairs file reviewed by local media } \\
\text { stations. }\end{array}$ & \\
\hline & & $\begin{array}{l}\text { The portraying an incident which I was involved as } \\
\text { police brutality. }\end{array}$ & \\
\hline
\end{tabular}

Depression. Agnew (1992) described negative affect as a range of negative emotional states that occurred in response to strain, such as disappointment, depression, despair, fear, and anger. Negative emotional states produced pressure for corrective action; decreased the ability to engage in legal coping and perceived costs of crime; and created a disposition for delinquency and crime. Depression resulted when individuals experienced a disliked event or condition. Depressed individuals felt powerless or unable 
to change the disliked state of affairs and became inactive, lethargic, and listless. Emotions closely related to depression included anguish, despair, hopelessness, and disappointment (Agnew, 2006). For the current study, a depression measure comprised of four items was constructed from the HSI to examine various symptoms of depression $(\alpha=0.82)$ (See Table 2). Each item required participants to indicate how frequently they experienced certain stress symptoms over the past month on a seven-point Likert-scale. The original response categories ranged from -3 (a lot less than usual for me) to +3 (a lot more than usual for me). The response categories were recoded such that $1=\mathrm{A}$ lot less than usual for me/Moderately less than usual for me/Slightly less than usual for me/Same as usual for me, 2 = Slightly more than usual for me, $3=$ Moderately more than usual for me, and 4 = A lot more than usual for me. The depression measure was scaled directionally, with higher scores suggesting greater symptoms of depression experienced among participants.

The HSI is a self-report measure that assesses cognitive, behavioral, affective, and physical symptoms of stress. The HSI is comprised of 89 items divided into four subscales, including Mood Disturbances, Sense of Urgency, Physiological, and Acting Out Behaviors (High, 2015). Apart from the current study, the HSI has never been assessed with a sample of police officers. 
Table 2.

\begin{tabular}{lc} 
Depression Measure & \\
\hline \multicolumn{1}{c}{ Item Description } & $\begin{array}{c}\text { Cronbach's } \\
\text { Alpha }\end{array}$ \\
\hline Lack of focus. & \\
Feelings of depression. & 0.82 \\
Decreased interest in hobbies. & \\
Feeling mentally dull. & \\
\hline
\end{tabular}

Substance use as coping. Agnew (1992) proposed a typology of cognitive, behavioral, and emotional adaptations to strain, with each serving as a mechanism to reduce or eliminate negative emotional states produced by strain. For the current study, a substance use as coping measure comprised of three items was constructed from the COPE to examine how frequently police officers responded to strain with drug and alcohol use $(\alpha=0.73)$ (See Table 3). Each item required participants to indicate how often they used certain coping strategies on a four-point Likert-scale. The response categories were coded such that $1=\mathrm{I}$ usually don't do this at all, 2 = I usually do this a little bit, $3=\mathrm{I}$ usually do this a medium amount, and $4=\mathrm{I}$ usually do this a lot. The substance use as coping measure was scaled directionally, with higher scores suggesting greater frequency of substance use as a form of coping among participants.

The COPE is a self-report measure that assesses a broad range of useful and less functional coping strategies. The COPE is comprised of 60 items divided into 15 subscales that examine various problem-focused (i.e., active coping, planning, suppression of competing activities, restraint coping, instrumental social support), emotion-focused (i.e., positive reinterpretation, acceptance, denial, turning to religion, emotional social support), less useful (i.e., venting, mental disengagement, behavioral 
disengagement), and recently developed (i.e., substance abuse, humor) coping strategies (Carver, Scheier, \& Weintraub, 1989; Litman, 2006). The COPE has previously been administered to police officers employed in various types and sizes of law enforcement agencies throughout Australia (Burke \& Paton, 2006), Singapore (Bishop et al., 2001), South Africa (Louw \& Viviers, 2010), and the United States (Haisch \& Meyers, 2004) among others.

Table 3.

Substance Use as Coping Measure

\begin{tabular}{lc}
\hline \multicolumn{1}{c}{ Item Description } & $\begin{array}{c}\text { Cronbach's } \\
\text { Alpha }\end{array}$ \\
\hline I use alcohol or drugs to make myself feel better. & \\
I drink alcohol or take drugs in order to think about it less. & 0.73 \\
I use alcohol or drugs to help me get through it. & \\
\hline
\end{tabular}

Sociodemographic characteristics. Several sociodemographic characteristics were assessed to describe the sample, including age, gender, race, police rank, marital status, and level of education. Age was measured by an open-ended question. Apart from age, all sociodemographic measures met the criteria for nominal levels of measurement; therefore, they were recoded to construct dummy variables to sort participant data into mutually exclusive categories (See Table 4). Sociodemographic characteristics were only examined to obtain contextual information about the sample and were not included in the bivariate or multivariate analyses. 
Table 4.

Sociodemographic Characteristics

\begin{tabular}{lll}
\hline \multicolumn{1}{c}{ Measure } & \multicolumn{2}{c}{ Dummy Code } \\
\hline Gender & 1 = Male & $0=$ Female \\
Race & $1=$ White & $0=$ Non-White \\
Police Rank & $1=$ Commanding Officer & $0=$ Patrol Officer \\
Marital Status & $1=$ Married & $0=$ Single \\
Level of Education & $1=$ College Degree & $0=$ Non-College Degree \\
& & \\
\hline
\end{tabular}

\section{Analytic Strategy}

The current study examined multiple research hypotheses using structural equation modeling (SEM) to determine whether GST could explain strain, depression, and substance use as a form of coping among police officers. SEM is used to describe a model based on theoretical knowledge. The model is suited to test a priori defined relations among latent measures. Latent measures are characterized as the theoretical concepts that cannot be observed directly. In a typical SEM, a latent measure is represented as a factor comprised of multiple observed indicators. The model is statistically tested against a sample to examine how well the model describes the data (Cheng, 2006; Manzoni \& Eisner 2006). SEM was selected over other multivariate statistics because depression was expected to mediate the relationship between strain and substance use as a form of coping. SEM was also recommended since it can examine multiple research hypotheses simultaneously with less measurement error. SEM was presented as a set of statistical tests that included two components: (1) measurement model and (2) structural model. The following steps describe the series of statistical tests 
that were conducted, beginning with the descriptive statistics and ending with the latent structural models. Step 1 was computed using SPSS V25.0, while Steps 2-5 were conducted using Mplus V7.0.

The univariate statistics were calculated in Step 1. The minimum, maximum, mean, standard deviation, skewness, and kurtosis were computed to examine the distribution of the data. The minimum represents the smallest value in the distribution, while the maximum represents the largest value. The minimum and maximum help define the range of values in the distribution. The mean denotes the average score in a distribution and is computed by using the value of each score in the distribution. Standard deviation is a measure of dispersion of the scores around the mean and is computed by subtracting the mean from each score in the distribution. High standard deviation values mean that the scores are farther from the mean of the distribution, while low standard deviation values indicate that the scores are closer to the mean of the distribution (Vito, Blankenship, \& Kunselman, 2008). Skewness is an index that reflects the lack of symmetry of a univariate distribution, while kurtosis measures the shape of the distribution in terms of its peakedness relative to a corresponding normal distribution (Raykov \& Marcoulides, 2006). Normality of the data is determined when the skewness is below three and kurtosis is below 10 (Kline, 2016).

Step 1 also compared select sociodemographic characteristics across the sample data and data from the most recent Law Enforcement Management and Administrative Statistics Survey (LEMAS) (United States Department of Justice, Office of Justice Programs, Bureau of Justice Statistics, 2015). The LEMAS collects data from a nationally representative sample of state and local law enforcement agencies throughout 
the United States. LEMAS (2013) data were obtained from 2,059 local police departments, 717 sheriff's offices, and 46 state law enforcement agencies. The percent and frequency were computed for gender, race, and police rank in both the study sample (2016) and LEMAS (2013) data to determine if the sociodemographic characteristics obtained in the sample data were similar to those in a nationally representative sample.

The bivariate statistics were calculated in Step 2. Since all independent and dependent measures in the current study met the criteria for ordinal levels of measurement, polychoric correlation coefficients were computed to examine the strength and direction of the relationship between the measures. Solutions obtained using polychoric correlation coefficients provide a more accurate reproduction of the confirmatory factor analysis (CFA) or measurement model used to generate the data (Holgado-Tello, Chacon-Moscoso, Barbero-Garcia, \& Vila-Abad, 2010). Special attention was paid to the levels of covariation among the measures to ensure that they were not collinear. Multicollinearity exists when there are high intercorrelations among the independent measures. Although some degree of multicollinearity is generally present in most datasets, it is important to examine measures that are very highly correlated (i.e., close to +/-1), as highly collinear measures can lead to serious statistical problems and unreliable inferences (Yu, Jiang, \& Land, 2015).

Step 3 was the presentation of the CFA or measurement model. CFA is a statistical technique that falls under the general category of SEM (Cheng, 2006). The primary aim of CFA is to examine the patterns of interrelationships among the latent measures and observed indicators to determine whether the proposed model fits the sample data. Each observed indicator is assumed to have two underlying causes: (1) the 
factor the observed indicator is supposed to measure, and (2) the error terms that comprise all other sources of causation (Cheng, 2006). Discriminant and convergent validity of the measures are determined by examining factor loadings (i.e., 0.50 and above) and multiple fit indices (Kline, 2016).

According to Hooper, Coughlan, and Mullen (2008), assessing whether a specified model fits the data is one of the most important steps in SEM (See Table 5). Absolute fit indices evaluate the overall difference between the observed and modelimplied covariance. Absolute fit indices determine how well an a priori model fits the sample data and demonstrates how well the proposed theory fits the data. The absolute fit indices do not rely on comparison with a baseline model but measure how well the model fits in comparison to no model at all (Hooper et al., 2008). The primary types of absolute model fit for the study included the chi-square and standardized root mean of the residual (SRMR). The chi-square measures the discrepancy between predicted and observed covariances, while the SRMR measures the overall difference between predicted and observed correlations. A significant chi-square indicates that the hypothesized model does not fit well with the sample data (Cheng, 2006).

Parsimonious fit indices evaluate the overall difference between the observed and model-implied covariance and consider the simplicity of the model. The root mean squared error of approximation (RMSEA) was the primary type of parsimonious fit considered in the study. The RMSEA measures the discrepancy between predicted and observed covariances divided by the degrees of freedom (Cheng, 2006).

Incremental fit indices evaluate the model's absolute or parsimonious fit relative to a baseline model, which is usually the null model. The comparative fit index (CFI) 
was the primary type of incremental fit considered in the study. The CFI compares the covariance matrices of the theoretical model to the observed model and the observed model to the null model, where all latent measures are expected to be uncorrelated. Comparing the covariance matrices allows researchers to examine the improvement in fit in moving from the null model to the theoretical model (Cheng, 2006).

Each fit statistic employs a different methodology and will sometimes generate contradictory results. For example, one fit statistic may meet the cutoff criteria but another fit statistic in the same model will not. A model with good overall fit with the sample data indicates that the relations in the model are consistent with those in the sample data, while a model with poor overall fit with the sample data suggests that the relations in the model are not consistent with those in the sample data (Cheng, 2006). Proper model fit occurs when the chi-square is nonsignificant; however, since the chisquare is sensitive to large sample size (i.e., 200 and more), it is important to consider other fit indices. Model fit is considered good when the SRMR is below 0.05, RMSEA is below 0.06, and CFI is above 0.95 (Kline, 2016). 
Table 5.

Goodness-of-Fit Measures

\begin{tabular}{|c|c|c|c|}
\hline Type of Fit & Fit Index & Definition of Fit Index & $\begin{array}{l}\text { Proper Fit } \\
\text { Standard }\end{array}$ \\
\hline \multirow[b]{2}{*}{ Absolute } & Chi-Square & $\begin{array}{l}\text { Measures the discrepancy between } \\
\text { predicted and observed covariances. }\end{array}$ & Nonsignificant \\
\hline & SRMR & $\begin{array}{l}\text { Measures the overall difference between } \\
\text { predicted and observed correlations. }\end{array}$ & $<0.05$ \\
\hline Parsimonious & RMSEA & $\begin{array}{l}\text { Measures the discrepancy between } \\
\text { predicted and observed covariances } \\
\text { divided by the degrees of freedom. }\end{array}$ & $<0.06$ \\
\hline Incremental & CFI & $\begin{array}{l}\text { Compares the covariance matrixes of the } \\
\text { theoretical model to the observed model } \\
\text { and the observed model to the null model. }\end{array}$ & $>0.95$ \\
\hline
\end{tabular}

Step 4 examined the structural models. The mediating effect of depression on the relationship between strain (i.e., financial problems, time away from family, media scrutiny) and substance use as a form of coping was assessed use using SEM. Model fit was examined using the same indices and standards in the CFA to determine the adequacy of Model 1.

Step 5 conducted alternative SEMs to determine whether the effects found in Step 4 could be replicated. Model 2 examined whether strain and depression had independent direct effects on substance use as a form of coping, while Model 3 tested whether strain had an indirect effect on substance use as a form of coping through depression while maintaining a direct effect on substance use as a form of coping. Model fit was examined using the same indices and standards in Steps 3-4 to determine the adequacy of Models 23. 


\section{CHAPTER IV}

\section{RESULTS}

\section{Step 1}

Table 6 contains the descriptive statistics for select sociodemographic characteristics for both the study sample (2016) and Law Enforcement Management and Administrative Statistics Survey (LEMAS) (2013) data. While both the study sample (2016) and LEMAS (2013) data contained multiple sociodemographic measures, gender, race, and police rank were the only measures that could be assessed across both datasets. Results indicated that while the number of male police officers was similar in both data ( $84 \%$ and $83 \%$, respectively), there were more white officers in the study sample $(76 \%)$ than the nationally representative sample (52\%). It could be assumed that the LEMAS (2013) data captured greater racial diversity among participants since it was a nationally representative sample; the study sample (2016) data was limited to a particular geographical region. Results also revealed that there were fewer commanding officers in the study sample $(15 \%)$ than the nationally representative sample $(30 \%)$. It is possible that the size of the police agency in the study sample limited the number of commanding officer positions available, whereas the nationally representative sample could have included much larger police agencies with more of these positions, such as New York Police Department, Chicago Police Department, and Los Angeles County Sheriff's 
Department among others. Overall, results demonstrated that the sociodemographic characteristics obtained in the study sample were not vastly different from those in a nationally representative sample of state and local law enforcement agencies.

Table 6

Comparison of Study Sample and Nationally Representative Sample

\begin{tabular}{|c|c|c|}
\hline Measure & $\begin{array}{c}\text { Study Sample (2016) } \\
\qquad \%(\mathrm{~N})\end{array}$ & $\begin{array}{c}\text { LEMAS (2013) } \\
\%(\mathrm{~N})\end{array}$ \\
\hline Gender (i.e., Male) & $84(185)$ & $83(28,630)$ \\
\hline Race (i.e., White) & $76(165)$ & $52(17,979)$ \\
\hline $\begin{array}{l}\text { Police Rank (i.e., Commanding } \\
\text { Officer) }\end{array}$ & $15(33)$ & $30(7,806)$ \\
\hline
\end{tabular}

Table 7 contains the descriptive statistics for all measures in the study sample (2016) data. The average age of participants was $31.34(\mathrm{Min}=18.00, \mathrm{Max}=56.00, \mathrm{SD}=$ 8.45). The majority of participants identified as white (76\%) males (84\%) with a police rank of patrol officer (85\%). Almost half (46\%) of participants were married, and $42 \%$ possessed a college degree.

Results suggested that participants felt strain in the form of financial problems $(\operatorname{Min}=5.00, \operatorname{Max}=20.00$, Mean $=9.25, \mathrm{SD}=3.76$, Skewness $=0.33$, Kurtosis $=-1.40)$ was mildly stressful for them. Participants also felt strain in the form of time away from family $(\operatorname{Min}=4.00, \operatorname{Max}=16.00$, Mean $=9.59, \mathrm{SD}=3.19$, Skewness $=0.05$, Kurtosis $=$ -0.60) was moderately stressful for them. Lastly, participants felt strain in the form of media scrutiny $(\mathrm{Min}=5.00, \operatorname{Max}=20.00$, Mean $=11.65, \mathrm{SD}=4.50$, Skewness $=0.12$, Kurtosis $=-1.07$ ) was moderately stressful for them. In sum, strain in the form of financial problems was less stressful for participants than both time away from family and media scrutiny. The results are significant to the current study's utilization of 
general strain theory (GST). Agnew (2006) defined strain as an event or condition that was disliked by individuals. Recent empirical studies testing predictions of GST identified various operational and organizational aspects of policing known to cultivate strain among officers, including dangerous work-related events (Bishopp et al, 2018; Gibson et al., 2001; Swatt et al., 2007; Yun \& Lee, 2015), bureaucratic characteristics (Yun \& Lee, 2015), limited family time (Moon \& Jonson, 2012), income, and on-duty injuries (Shim et al., 2015) among others. Like other research (Moon \& Jonson, 2012; Shim et al., 2015), the findings in the current study revealed that participants experienced mild to moderate strain due to problematic income and limited family time as a result of their job, offering support for Agnew's (1992) contention that strain resulted when individuals experienced goal blockage, lost something that they valued, or encountered negatively valued stimuli.

Results also demonstrated that participants did not experience symptoms of depression, including a lack of focus $(\mathrm{Min}=1.00, \operatorname{Max}=4.00$, Mean $=1.15, \mathrm{SD}=0.45$, Skewness $=3.03$, Kurtosis $=8.49)$ or feelings of depression $(\operatorname{Min}=1.00, \operatorname{Max}=4.00$, Mean $=1.13, \mathrm{SD}=0.39$, Skewness $=3.09$, Kurtosis $=9.44)$. Participants also did not experience decreased interest in hobbies $(\operatorname{Min}=1.00, \operatorname{Max}=4.00$, Mean $=1.18, \mathrm{SD}=$ 0.62 , Skewness $=3.83$, Kurtosis $=14.08)$ or feeling mentally dull $(\operatorname{Min}=1.00, \operatorname{Max}=$ 4.00, Mean $=1.14, \mathrm{SD}=0.47$, Skewness $=3.97$, Kurtosis $=16.93)$. All four items that comprised the depression measure did not meet the threshold for normality (i.e., skewness $<3$, kurtosis $<10$ ). These findings are also significant to the current study's utilization of GST. Agnew (1992) purported that negative emotional states (e.g., depression, anxiety, anger) resulted when individuals encountered strain. Several studies 
(Bishopp et al., 2018; Gibson et al., 2001; Shim et al., 2015; Swatt et al., 2007; Yun \& Lee, 2015) examining the generality of GST among police officers concluded that various police-oriented strains directly impacted measures of negative affect, including depression. The items that comprised the depression measure in the current study were similar to the depression measures noted in these more recent police studies. Participants experienced mild to moderate strain in the form of financial problems, time away from family, and media scrutiny but did not endorse any symptoms of depression. While the univariate analysis did not examine the relationship between strain and depression, the findings raise questions regarding the veracity of Agnew's (1992) argument that strain produces negative emotional states.

Results indicated that participants usually used drugs or alcohol a little bit to make themselves feel better $(\operatorname{Min}=1.00, \operatorname{Max}=4.00$, Mean $=1.36, \mathrm{SD}=0.70$, Skewness $=2.28$, Kurtosis $=5.21$ ). Participants also usually used drugs or alcohol a little bit to think about it less $(\mathrm{Min}=1.00, \mathrm{Max}=4.00$, Mean $=1.46, \mathrm{SD}=0.82$, Skewness $=1.70$, Kurtosis $=1.80$ ). Lastly, participants usually used drugs or alcohol a little bit to help them get through it $(\mathrm{Min}=1.00, \mathrm{Max}=4.00$, Mean $=1.86, \mathrm{SD}=1.04$, Skewness $=0.83$, Kurtosis $=-0.68$ ). Like the strain and depression results, these findings are significant to the current study's utilization of GST. Agnew (1992) introduced a typology of cognitive, behavioral, and emotional adaptations to strain, with each acting as a mechanism to reduce or eliminate negative emotional states produced by strain. Recent empirical studies have examined the utility of GST in explaining alcohol consumption among police officers. For example, Swatt et al. (2007) concluded that depression mediated the effect of work-related strain on problematic alcohol consumption. Likewise, Yun and 
Lee (2015) found that depression mediated the relationship between organizational strain and hazardous alcohol consumption. Although participants usually used drugs or alcohol a little bit to cope with their strain in the current study, they did not report any symptoms of depression. While the univariate analysis did not examine the relationships between strain, depression, and substance use as a form of coping, the findings raise questions regarding the veracity of Agnew's (1992) proposition that negative emotional states prepared individuals to engage in various coping strategies to lessen negative affect produced by strain. However, the results may support the current study's hypothesis that strain would have a direct effect on substance use as a form of coping since participants reported mild to moderate levels of both strain and substance use as a form of coping. 
Table 7

Descriptive Statistics

\begin{tabular}{|c|c|c|c|c|c|c|}
\hline Measure & Minimum & Maximum & Mean & $\mathrm{SD}$ & Skewness & Kurtosis \\
\hline Age & 18.00 & 56.00 & 31.34 & 8.45 & 0.84 & -0.12 \\
\hline Gender (i.e., Male) & 0.00 & 1.00 & 0.84 & -- & -1.88 & 1.54 \\
\hline Race (i.e., White) & 0.00 & 1.00 & 0.76 & -- & -1.23 & -0.50 \\
\hline $\begin{array}{l}\text { Police Rank (i.e., } \\
\text { Commanding Officer) }\end{array}$ & 0.00 & 1.00 & 0.15 & -- & 1.98 & 1.94 \\
\hline Marital Status (i.e., Married) & 0.00 & 1.00 & 0.46 & -- & 0.17 & -1.99 \\
\hline $\begin{array}{l}\text { Level of Education (i.e., } \\
\text { College Degree) }\end{array}$ & 0.00 & 1.00 & 0.42 & -- & 0.33 & -1.91 \\
\hline Financial Problems & 5.00 & 20.00 & 9.25 & 3.76 & 0.33 & -1.40 \\
\hline Time Away from Family & 4.00 & 16.00 & 9.59 & 3.19 & 0.05 & -0.60 \\
\hline Media Scrutiny & 5.00 & 20.00 & 11.65 & 4.50 & 0.12 & -1.07 \\
\hline Lack of Focus & 1.00 & 4.00 & 1.15 & 0.45 & 3.03 & 8.49 \\
\hline Feelings of Depression & 1.00 & 4.00 & 1.13 & 0.39 & 3.09 & 9.44 \\
\hline Decreased Interest in Hobbies & 1.00 & 4.00 & 1.18 & 0.62 & 3.83 & 14.08 \\
\hline Feeling Mentally Dull & 1.00 & 4.00 & 1.14 & 0.47 & 3.97 & 16.93 \\
\hline $\begin{array}{l}\text { I use drugs or alcohol to make } \\
\text { myself feel better }\end{array}$ & 1.00 & 4.00 & 1.36 & 0.70 & 2.28 & 5.21 \\
\hline $\begin{array}{l}\text { I drink alcohol or take drugs } \\
\text { in order to think about it less }\end{array}$ & 1.00 & 4.00 & 1.46 & 0.82 & 1.70 & 1.80 \\
\hline $\begin{array}{l}\text { I use alcohol or drugs to help } \\
\text { me get through it }\end{array}$ & 1.00 & 4.00 & 1.86 & 1.04 & 0.83 & -0.68 \\
\hline
\end{tabular}

\section{Step 2}

Table 8 contains the polychoric correlation matrix for the measures. Results of the correlation matrix depict several statistically significant relationships. More specifically, feeling mentally dull $(r=0.75, p<0.05)$ was positively and strongly 
correlated with decreased interest in hobbies. Feeling mentally dull $(r=0.68, p<0.05)$, decreased interest in hobbies $(r=0.57, p<0.05)$, and feelings of depression $(r=0.35, p$ $<0.05)$ were all positively and moderately correlated with lack of focus. I use drugs or alcohol to make myself feel better $(r=0.62, p<0.05)$ was positively and moderately correlated with I drink alcohol or take drugs in order to think about it less. Feelings of depression $(r=0.53, p<0.05)$ was positively and moderately correlated with decreased interest in hobbies. I drink alcohol or take drugs in order to think about it less $(r=0.53, p$ $<0.05)$ and I use drugs or alcohol to make myself feel better $(r=0.35, p<0.05)$ were both positively and moderately correlated with I use alcohol or drugs to help me get through it. Financial problems $(r=0.48, p<0.05)$ and time away from family $(r=0.45$, $p<0.05)$ were both positively and moderately correlated with media scrutiny. Feelings of depression $(r=0.28, p<0.05)$ was positively and weakly correlated with feeling mentally dull. Media scrutiny $(r=0.22, p<0.05)$ was positively and weakly correlated with I drink alcohol or take drugs in order to think about it less. Financial problems $(r=$ $0.18, p<0.05)$ was positively and weakly correlated with time away from family. Media scrutiny $(r=0.16, p<0.05)$ was positively and weakly correlated with I use alcohol or drugs to help me get through it. Financial problems $(r=0.15, p<0.05)$ was positively and weakly correlated with I drink alcohol or take drugs in order to think about it less. Results of the bivariate analysis are relevant to the current study's hypothesis since strain was positively associated with substance use as a form of coping. In other words, participants who experienced higher levels of strain in the form of financial problems and media scrutiny also reported greater frequency of substance use as a form of coping. In some ways, this finding is consistent with previous research that examined 
predictions of GST to explain problematic alcohol consumption among police officers.

For example, both Swatt et al. (2007) and Yun and Lee (2015) found that different forms of strain were related to greater levels of hazardous alcohol consumption among officers. Multivariate analysis is necessary to isolate the effects of strain. Overall, results of the correlation matrix demonstrated enough shared variance to proceed to the structural equation modeling (SEM) analysis. 
Table 8

Polychoric Correlation Matrix

\begin{tabular}{|c|c|c|c|c|c|c|c|c|c|c|}
\hline Measure & 1 & 2 & 3 & 4 & 5 & 6 & 7 & 8 & 9 & 10 \\
\hline 1. Financial Problems & 1.00 & & & & & & & & & \\
\hline 2. Time Away from Family & $0.18^{*}$ & 1.00 & & & & & & & & \\
\hline 3. Media Scrutiny & $0.48^{*}$ & $0.45^{*}$ & 1.00 & & & & & & & \\
\hline 4. Lack of Focus & 0.04 & -0.04 & 0.07 & 1.00 & & & & & & \\
\hline 5. Feelings of Depression & -0.01 & -0.05 & 0.05 & $0.35 *$ & 1.00 & & & & & \\
\hline 6. Decreased Interest in Hobbies & -0.05 & -0.06 & 0.01 & $0.57^{*}$ & $0.53^{*}$ & 1.00 & & & & \\
\hline 7. Feeling Mentally Dull & 0.05 & 0.02 & 0.08 & $0.68^{*}$ & $0.28 *$ & $0.75^{*}$ & 1.00 & & & \\
\hline 8. I use drugs or alcohol to make myself feel better & -0.01 & -0.06 & 0.04 & 0.04 & -0.03 & -0.00 & 0.06 & 1.00 & & \\
\hline 9. I drink alcohol or take drugs in order to think about it less & $0.15^{*}$ & 0.09 & $0.22 *$ & -0.09 & -0.09 & -0.06 & 0.00 & $0.62 *$ & 1.00 & \\
\hline 10. I use alcohol or drugs to help me get through it & 0.06 & 0.10 & $0.16^{*}$ & -0.06 & -0.04 & -0.06 & -0.01 & $0.35^{*}$ & $0.53 *$ & 1.00 \\
\hline
\end{tabular}




\section{Step 3}

To develop the confirmatory factor analysis (CFA) or measurement model, three summative scales were constructed from the Spina Officer Scale (SOS) to form the latent strain measure. In addition, four observed indicators were selected from the High Stress Inventory (HSI) to represent the latent depression measure, while three observed indicators were selected from the COPE Inventory (COPE) to represent the latent substance use as coping measure. Table 9 and Figure 3 contain the results of the CFA.

Results demonstrated that the fit of the measurement model to the sample data was very good. More specifically, the chi-square was not statistically significant $\left(\chi^{2}=\right.$ $32.70, d f=31, p=0.38)$, and the other fit indices $(\mathrm{SRMR}=0.04, \mathrm{RMSEA}=0.02, \mathrm{CFI}=$ 1.00) met proper fit standards specified in the analytic strategy (See Table 5), suggesting that the measurement model found proper construct validity for the measures used in the current study.

Results also revealed that all but two factor loadings for the observed indicators were above Kline's (2016) standard of 0.50 for a large factor loading. Furthermore, all factor loadings were statistically significant, indicating proper levels of discriminant and convergent validity. Neither the financial problems nor time away from family measures of strain had a large factor loading ( 0.45 and 0.43 , respectively); however, both measures were retained due to their theoretical (Agnew, 1992) and empirical relevance to the current study. Overall, both the size and significance of the factor loadings indicated that the proposed measures were sufficient observed indicators of their hypothesized latent measures. 
The findings offered support for Agnew's (1992) contention that there were three primary categories of strain. The three summative scales that comprised the latent strain measure were sufficient measures of strain in the form of the actual or anticipated failure to achieve positively valued stimuli (i.e., financial problems), actual or anticipated removal of positively valued stimuli (i.e., time away from family), and actual or anticipated presentation of negatively valued stimuli (i.e., media scrutiny). The findings also supported Agnew's (2006) proposition that depression occurred when individuals experienced a disliked event or condition. Depressed individuals felt powerless or unable to change the disliked state of affairs and became inactive, lethargic, and listless (Agnew, 2006). The four observed indicators that comprised the latent depression measure sufficiently measured symptoms of depression as described by Agnew (2006). Lastly, the findings were in line with Agnew's (1992) argument that various adaptations to strain served as a mechanism to reduce or eliminate negative emotional states produced by strain. The three observed indicators that comprised the latent substance use as coping measure were sufficient measures of coping behaviors (e.g., "I use alcohol or drugs to make myself feel better") outlined in GST. 
Table 9

Measurement Model

\begin{tabular}{|c|c|c|}
\hline Latent Measure & Observed Indicator & Factor Loading \\
\hline \multirow[t]{3}{*}{ Strain } & Financial Problems & $0.45 * *$ \\
\hline & Time Away from Family & $0.43 * *$ \\
\hline & Media Scrutiny & $1.00 * *$ \\
\hline \multirow[t]{4}{*}{ Depression } & Lack of Focus & $0.69 * *$ \\
\hline & Feelings of Depression & $0.60 * *$ \\
\hline & Decreased Interest in Hobbies & $0.82 * *$ \\
\hline & Feeling Mentally Dull & $0.93 * *$ \\
\hline \multirow[t]{3}{*}{$\begin{array}{l}\text { Substance Use } \\
\text { as Coping }\end{array}$} & $\begin{array}{l}\text { I use drugs or alcohol to make myself feel } \\
\text { better }\end{array}$ & $0.62 * *$ \\
\hline & $\begin{array}{l}\text { I drink alcohol or take drugs in order to } \\
\text { think about it less }\end{array}$ & $0.99 * *$ \\
\hline & $\begin{array}{l}\text { I use alcohol or drugs to help me get } \\
\text { through it }\end{array}$ & $0.53 * *$ \\
\hline Chi-Square Test of Model Fit $\left(\chi^{2}\right)$ & \multicolumn{2}{|l|}{32.70} \\
\hline $\begin{array}{l}\text { Standardized Root Mean of the } \\
\text { Residual (SRMR) }\end{array}$ & \multicolumn{2}{|l|}{0.04} \\
\hline $\begin{array}{l}\text { Root Mean Squared Error } \\
\text { Approximation (RMSEA) }\end{array}$ & \multicolumn{2}{|l|}{0.02} \\
\hline Confirmatory Fit Index (CFI) & \multicolumn{2}{|l|}{1.00} \\
\hline
\end{tabular}

Note: $* * p<0.01$.

Figure 3. Measurement Model

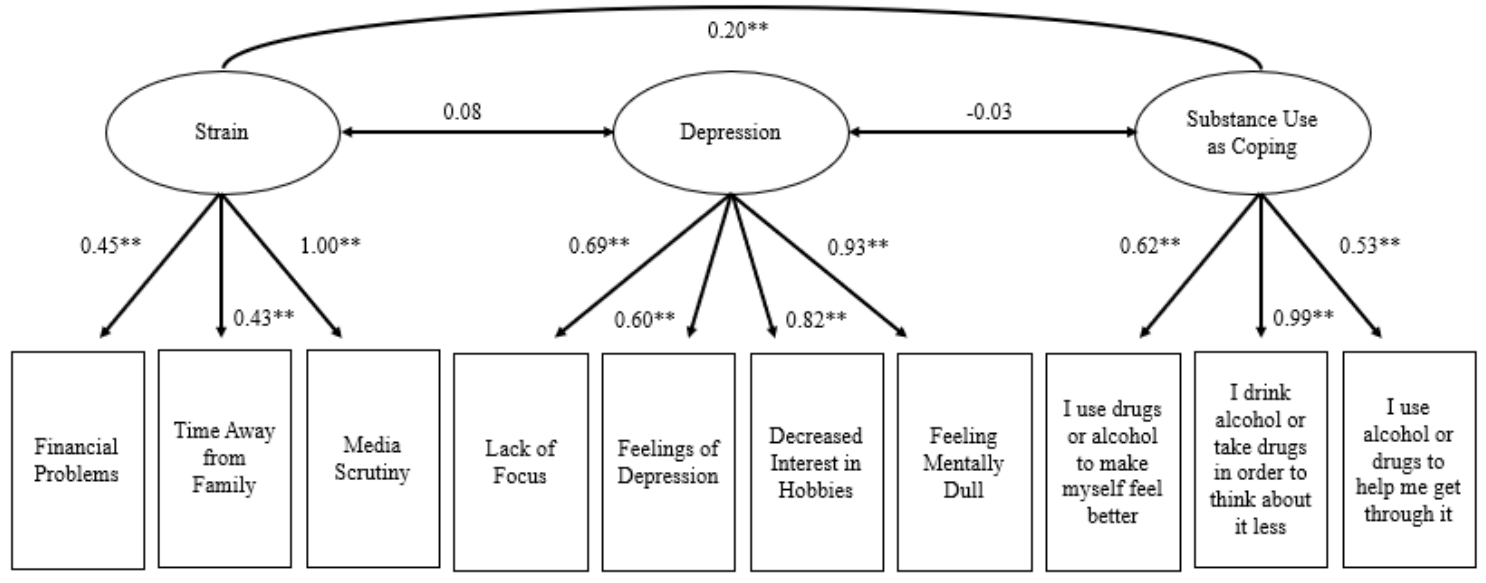

Step 4

Table 10 and Figure 4 contain the results of the indirect effects structural model, which tested whether strain had an indirect effect on substance use as a form of coping through depression. Results demonstrated that the fit of the structural model to the 
sample data was very good. More specifically, the chi-square was not statistically significant $\left(\chi^{2}=42.96, d f=32, p=0.09\right)$, and the other fit indices $(\mathrm{SRMR}=0.05$, RMSEA $=0.04, \mathrm{CFI}=1.00)$ met proper fit standards specified in the analytic strategy (See Table 5).

Results also indicated that there were no statistically significant direct effects of strain on depression $(\beta=0.08, \mathrm{SE}=0.06, p=0.20)$ or depression on substance use as a form of coping $(\beta=-0.03, \mathrm{SE}=0.07, p=0.70)$, suggesting that depression did not mediate the link between strain and substance use as a form of coping. For a more comprehensive understanding of the sample data, additional depression measures not proposed for the analysis were also examined to determine if similar effects would be found, but the analysis yielded comparable findings.

The findings contrasted with previous theoretical literature that found that depression mediated the effect of work-related strain on problematic alcohol consumption among police officers (Swatt et al., 2007). Likewise, Yun and Lee (2015) concluded that the effects of organizational strain on hazardous alcohol use was mediated by depression among police officers, though the effect was not of great magnitude. Alternatively, results of the current study were consistent with other findings by Yun and Lee (2015), who concluded that operational strain's effect on being a drinker was not mediated by depression. Overall, Model 1 did not support the hypothesis of the current study that strain would have an indirect effect on substance use as a form of coping through depression. In this regard, Agnew's (1992) proposition that negative emotional states served as an intervening variable was not supported with the measures examined in this sample of police officers. 
Table 10

Indirect Effects Structural Model 1

\begin{tabular}{lcc}
\multicolumn{1}{c}{ Measure } & $\beta$ & SE \\
\hline Strain $\rightarrow$ Depression & 0.08 & 0.06 \\
Depression $\rightarrow$ Substance Use as Coping & -0.03 & 0.07 \\
\hline Chi-Square Test of Model Fit $(\chi 2)$ & 42.96 \\
Standardized Root Mean of the Residual (SRMR) & 0.05 \\
Root Mean Squared Error Approximation (RMSEA) & 0.04 \\
Confirmatory Fit Index (CFI) & 1.00 \\
\hline
\end{tabular}

Figure 4. Indirect Effects Structural Model 1

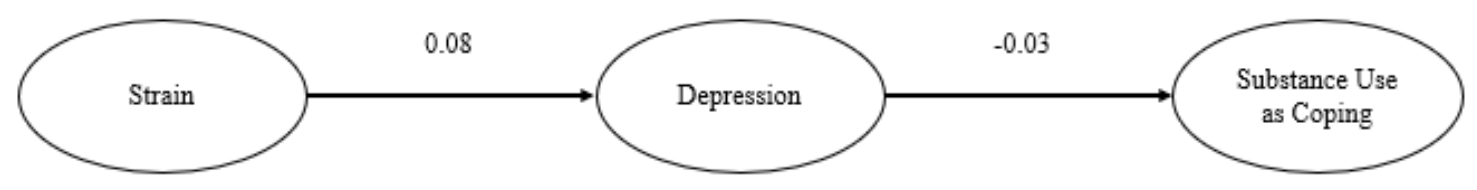

\section{Step 5}

Table 11 and Figure 5 contain the results of the first alternative structural model, which tested the independent direct effects of strain and depression on substance use as a form of coping. Results demonstrated that the fit of the structural model to the sample data was very good. More specifically, the chi-square was not statistically significant $\left(\chi^{2}\right.$ $=32.70, d f=31, p=0.38)$, and the other fit indices $(\mathrm{SRMR}=0.04, \mathrm{RMSEA}=0.02, \mathrm{CFI}$ $=1.00$ ) met proper fit standards specified in the analytic strategy (See Table 5). Results also indicated that while there was a statistically significant direct effect of strain on substance use as a form of coping $(\beta=0.21, \mathrm{SE}=0.07, p=0.00)$, depression did not produce a statistically significant direct effect on substance use as a form of coping ( $\beta=$ $0.05, \mathrm{SE}=0.07, p=0.49){ }^{1}$

\footnotetext{
${ }^{1}$ For a more comprehensive understanding of the sample data, additional depression measures not proposed for the analysis were also examined to determine if similar effects would be found, but the analysis yielded comparable findings.
} 
The findings contrasted with other research that found that depression was a significant predictor of hazardous alcohol consumption. Both Swatt et al. (2007) and Yun and Lee (2015) concluded that police officers who experienced greater levels of depression were more likely to become problematic alcohol drinkers. Alternatively, results of the current study were consistent with prior theoretical literature that found that both operational and organizational strains had significant impacts on alcohol use (Yun \& Lee, 2015). Overall, Model 2 supported the hypothesis of the current study that strain would have a direct effect on substance use as a form of coping.

Table 11

Direct Effects Structural Model 2

\begin{tabular}{lcc}
\hline \multicolumn{1}{c}{ Measure } & $\beta$ & SE \\
\hline Strain $\rightarrow$ Substance Use as Coping & $0.21^{* *}$ & 0.07 \\
Depression $\rightarrow$ Substance Use as Coping & -0.05 & 0.07 \\
\hline Chi-Square Test of Model Fit $(\chi 2)$ & \multicolumn{2}{c}{32.70} \\
Standardized Root Mean of the Residual (SRMR) & \multicolumn{2}{c}{0.04} \\
Root Mean Squared Error Approximation (RMSEA) & \multicolumn{2}{c}{0.02} \\
Confirmatory Fit Index (CFI) & \multicolumn{2}{c}{1.00} \\
\hline Note: $* * p<0.01$. &
\end{tabular}

Figure 5. Direct Effects Structural Model 2

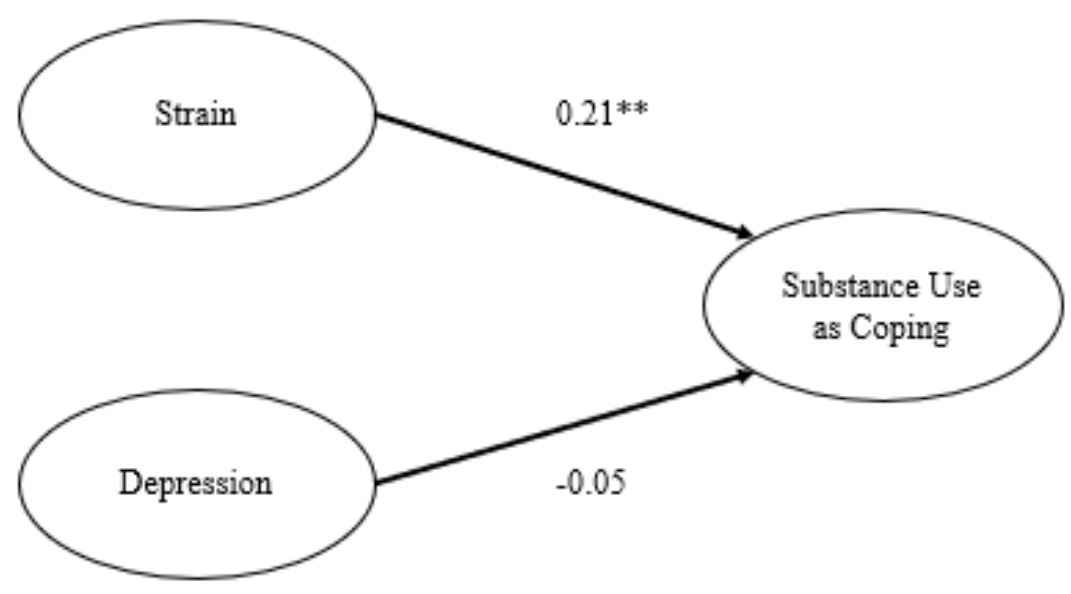


Table 12 and Figure 6 contain the results of the second alternative structural model, which tested whether strain had an indirect effect on substance use as a form of coping through depression while maintaining a direct effect on substance use as a form of coping. Results demonstrated that the fit of the structural model to the sample data was very good. More specifically, the chi-square was not statistically significant $\left(\chi^{2}=32.70\right.$, $d f=31, p=0.38)$, and the other fit indices $(\mathrm{SRMR}=0.04, \mathrm{RMSEA}=0.02, \mathrm{CFI}=1.00)$ met proper fit standards specified in the analytic strategy (See Table 5). Results also indicated that there were no statistically significant direct effects of strain on depression $(\beta=0.08, \mathrm{SE}=0.06, p=0.20)$ or depression on substance use as a form of coping $(\beta=-$ $0.05, \mathrm{SE}=0.07, p=0.49)$, suggesting that depression did not mediate the link between strain and substance use as a form of coping. Alternatively, strain did have a statistically significant direct effect on substance use as a form of coping $(\beta=0.21, \mathrm{SE}=0.07, p=$ $0.00) .^{1}$

The findings contrasted with previous theoretical literature that examined alcohol use among police officers. For example, Swatt et al. (2007) concluded that the relationship between work-related strain and problematic alcohol consumption was mediated by depression. Likewise, Yun and Lee (2015) found that depression mediated the effect of organizational strain on hazardous alcohol use, though the effect was not of great magnitude. Alternatively, results of the current study were consistent with other findings by Yun and Lee (2015), who's results regarding operational strain were not in line with the theoretical premise under study. When depression was included in their model, the significant relationship between operational strain and alcohol use did not dissipate. Contrary to GST, depression did not have a mediating effect on the 
relationship between operational strain and being a drinker. Additionally, both operational and organizational strains significantly affected alcohol consumption (Yun \& Lee, 2015). Overall, Model 3 supported the hypothesis of the current study that strain would have a direct effect on substance use as a form of coping; however, the model did not support the hypothesis that strain would have an indirect effect on substance use as a form of coping through depression. In this regard, Agnew's (1992) conjecture that negative emotional states served as an intervening variable was not supported with the measures examined in this sample of police officers.

Table 12

Direct and Indirect Effects Structural Model 3

\begin{tabular}{lcc}
\hline \multicolumn{1}{c}{ Measure } & $\beta$ & SE \\
\hline Strain $\rightarrow$ Depression & 0.08 & 0.06 \\
Strain $\rightarrow$ Substance Use as Coping & $0.21^{* *}$ & 0.07 \\
Depression $\rightarrow$ Substance Use as Coping & -0.05 & 0.07 \\
\hline Chi-Square Test of Model Fit ( $\chi 2)$ & 32.70 \\
Standardized Root Mean of the Residual (SRMR) & 0.04 \\
Root Mean Squared Error Approximation (RMSEA) & 0.02 \\
Confirmatory Fit Index (CFI) & 1.00 \\
\hline
\end{tabular}

Note: $* * p<0.01$.

Figure 6. Direct and Indirect Effects Structural Model 3

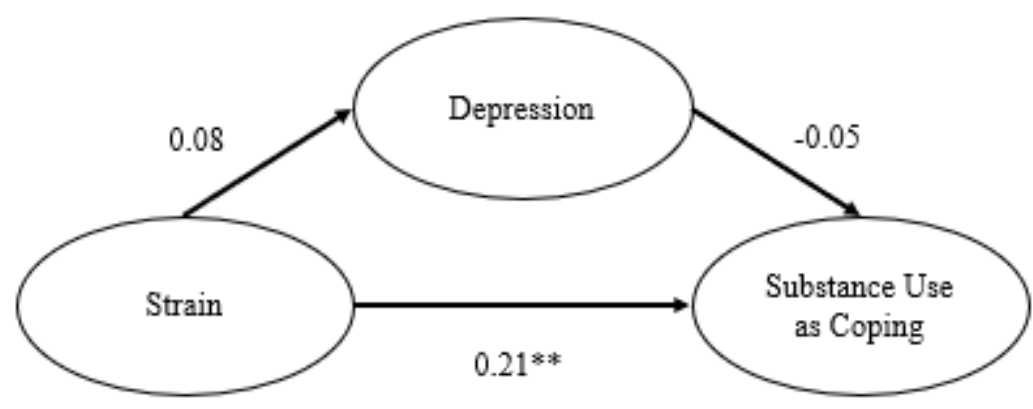




\section{CHAPTER V \\ DISCUSSION}

General strain theory (GST) has been applied by researches to examine strain, negative affect, and coping strategies believed to cultivate delinquency, crime, and maladaptive behaviors among adolescent, college, and police officer samples. Research on these samples generally offered support for GST; however, most studies failed to measure strain properly. More specifically, researchers measured strain with nonvalidated measures, limited items, or simplistic items that did not capture the various characteristics or dimensions of strain. In addition, researchers relied heavily on traditional regression analyses to test their hypotheses. The current study sought to overcome these limitations by exploring the utility of GST in explaining substance use as a form of coping among a sample of police officers in a Midwestern, metropolitan city using a validated police strain measure and rigorous statistical methods. More specifically, the investigation examined the mediating effect of depression on the relationship between strain and substance use as a form of coping. Based on GST's key propositions, it was hypothesized that police officers experiencing higher levels of strain would also experience greater symptoms of depression and frequency of substance use as a form of coping.

Univariate results demonstrated that the sociodemographic characteristics of sample participants were not vastly different from those in a nationally representative 
sample of state and local law enforcement agencies. While bivariate results revealed a significant association between strain and substance use as a form of coping, multivariate analysis was necessary to isolate the effects of strain.

Although results of the measurement model demonstrated that the proposed measures used in the current study were sufficient observed indicators of their hypothesized latent measures, generally, results of the analyses offered partial support for GST. Results of the indirect effects structural model (i.e., Model 1) indicated that strain did not have a statistically significant indirect effect on substance use as a form of coping through depression. Results of the first alternative structural model (i.e., Model 2) revealed that while there was a statistically significant direct effect of strain on substance use as a form of coping, depression did not produce a significant direct effect on substance use as a form of coping. Results of the second alternative structural model (i.e., Model 3) demonstrated that strain continued to exert a statistically significant effect on substance use as a form of coping, even after the inclusion of depression in the analysis; therefore, Agnew's (1992) contention that negative emotional states served as an intervening variable was not supported with the measures examined in this sample of police officers.

The findings in the current study contrasted with Swatt et al.'s (2007) study on police officers, who concluded that anxiety/depression mediated the relationship between work-related strain and drinking prevalence as well as work-related strain and problematic alcohol consumption. It is important to note, however, that Swatt et al. (2007) did not consider the three primary categories of strain and relied on traditional regression analyses to test hypotheses, ultimately limiting the measurement of the 
theoretical constructs under investigation and allowing for the possibility of other factors not considered in the analyses to account for the observed relationships.

Alternatively, results of the current study were consistent with Yun and Lee (2015), who concluded that none of their negative affect measures (i.e., anger, depression, and anxiety) mediated the relationship between operational strain and alcohol consumption. There are plausible explanations as to why no mediational effects were found in neither Yun and Lee (2015) nor the current study. For example, it is possible that depression symptoms could have manifested in other biological or psychological ways not captured in the police officers in the current study. More specifically, while men and women both experience depression, men who are depressed may appear angry, irritable, aggressive, or "on edge" and more likely to experience physical symptoms (e.g., racing heart, tightening chest, ongoing headaches, digestive issues). Alternatively, women who are depressed may present with more sadness, hopelessness, or flat affect (National Institute of Mental Health Office of Science Policy, Planning, and Communications, 2017). Given that $84 \%$ of the sample identified as male and the four observed indicators that comprised the latent depression measure targeted more classic symptoms of depression (e.g., feeling depressed, decreased interest in hobbies, mentally dull), these factors could account for the absence of mediational effects. It is also quite possible that strain may have an independent direct effect on substance use as a form of coping among police officers, irrespective of negative emotional states. Finally, considering the sample demographics, it is also plausible that police officers in the current study may have underreported or even falsified their responses in an effort to appear in a more favorable light (i.e., social desirability bias). Indeed, some officers may 
have been reluctant to disclose any history of depression due to suspicions and fears of being identified or negatively affected by the department.

\section{Policy Implications}

While results of the current study offered partial support for the generality of GST, the finding that police officers who experienced higher levels of strain in the form of financial problems, time away from family, and media scrutiny also reported greater frequency of substance use as a form of coping have important implications for police departments. For example, departments should consider placing police officers on rotated shifts and days off so that it is possible for them to have occasional evenings and weekends available to spend more quality time with their family. Police leaders must also recognize the varying levels of strain that their officers experience. In doing so, police leaders will have a better understanding of how to structure supervisor-subordinate relationships (e.g., transformational, authentic, in extremis, participative, or supportive leadership styles) and develop actionable strategies to minimize the adverse effects of strain, like depression and substance use (Chapin, Brannen, Singer, \& Walker, 2008; Russell, 2014).

Police administrators might consider collaborating with members of local news media to develop resolution strategies to improve police-media relations. Chrismas (2012) suggested that the police-media relationship is often strained due to contradictory needs and mandates within and between law enforcement agencies and media outlets. For example, news outlets experience great pressure to produce leading stories under tight publishing deadlines that beat out their competitors. Reporters frequently seek confidential police sources and information to relay to the public. The dynamic generates 
strain for police officers, who are under constant pressure to deliver effective messaging to demonstrate transparency and satisfy the public appetite for immediate, accurate information concerning crime, justice, and other community issues while also safeguarding sensitive information that cannot be released. Arranged meetings between police administrators and media managers to discuss the roles, mandates, challenges, and goals of each organization and develop shared solutions to structural or situational issues (e.g., new access times, providing updates on critical issues, extending public information office hours) may improve collaboration and communication among both groups (Chrismas, 2012). Improved collaboration and communication among police departments and local news media may increase effectiveness for both groups and reduce media-related strain among police officers.

Police departments are also encouraged to develop more comprehensive approaches to informing their officers on how to access employee assistance programs (EAPs) and other community resources, such as mental health counseling, peer-assistance teams, police psychologists, referrals by personal physicians, suicide prevention hotlines, and substance abuse treatment programs. For instance, in addition to including resource brochures in initial employment packets, departments could circulate periodic intranet or emails/fliers reminding officers of these services. Additionally, departments should engage officers in ongoing discussions about work-related strain by hosting formal (e.g., expert panel in a classroom setting) and informal (e.g., email links to high quality informational videos or podcasts) educational opportunities (Donnelly, Valentine, \& Oehme, 2015). 
Police departments are urged to incorporate comprehensive financial and preretirement training into their core training programs with the purpose of increasing financial health among officers. Early intervention and financial planning throughout the career offer officers the opportunity to make better and more informed decisions concerning their finances and reduce the likelihood of insufficient income during retirement. In addition, comprehensive financial planning is associated with less financial strain, overtime, and extra-duty jobs, allowing officers additional time for family and non-work activities. Police departments are encouraged to introduce officers to financial and pre-retirement training at the police academy or field training level and continue to offer trainings throughout the evolution of an entire career. Trainings should supply officers with a wide array of tools tailored for different age groups and career longevity and include topics related to household budgets, managing debt (e.g., credit card, student loans, mortgage), savings, investment options, pensions, retirement planning, benefits, legal affairs, tax strategy, funding education, etc. Police departments can leverage existing community resources by tapping into the expertise of financial specialists, planners, and advisors from local universities and financial institutions. Departments may also want to consider sending willing officers to train-the-trainer workshops so that they may provide ongoing instruction on personal finance and preretirement planning to employees at their local law enforcement agencies (Wukasch, 2017).

Police departments might also consider implementing evidence-based programs that reduce the emotional and behavioral consequences of strain. Early prevention of strain is important in halting the development of negative emotional states that 
subsequently influence substance use. Departments should introduce these programs to recruits in the police academy and then closely monitor their personnel and offer intervention services to veteran officers already experiencing high levels of strain. One such program has been implemented among a sample of police officers from seven departments in Santa Clara County, California. The HeartMath stress and emotional selfmanagement training offered police officers practical techniques designed to reduce stress in the moment, improve physiological and emotional balance, increase mental clarity, and enhance performance and quality of life. Throughout the training, police officers were taught to identify and recognize sources of stress and make perceptual and attitudinal shifts to modify negative mental and emotional responses to potential stressors. Several core techniques were employed throughout the training, including Freeze-Frame, Coherent Communication, and Heart Lock-In (McCraty, Tomasino, Atkinson, \& Sundram, 1999).

The Freeze-Frame technique instructed police officers to consciously disengage from negative and emotional responses as they were experienced by shifting their attention to the heart and generating a positive or neutral emotional state. In doing so, it prevented or reversed the body's normal destructive stress response and modified the bodily feedback sent to the brain. The Freeze-Frame technique promoted clearer thinking and transformed an inefficient, emotionally-draining response to a proactive one (McCraty et al., 1999).

The Coherent Communication technique facilitated the sharing of information with greater sincerity and effectiveness. Police officers learned to communicate more openly and disrupt their internal dialogue to listen to others more intently. It allowed 
police officers the opportunity to understand the essence of conversation and perceive additional levels of subtlety within information being communicated (McCraty et al., 1999).

The Heart Lock-In technique taught police officers to "lock-in" to a physiologically coherent state associated with improved cardiovascular function, reduced fatigue, heightened inner calm, and mental clarity. Police officers learned to focus their attention on the heart and experience a positive emotional state while listening to music specifically designed to promote stress reduction and physical, mental, and emotional regeneration. In short, the Heart Lock-In technique facilitated entrainment of physiological systems and helped balance heart rhythms, emotional states, and hormonal and autonomic function (McCraty et al., 1999).

In addition to the Freeze-Frame, Coherent Communication, and Heart Lock-In techniques, other tools were discussed in the program to help police officers apply key concepts and techniques learned to address work- and non-work-related stressors and actualize more of their core values at home and in the workplace. Several key benefits of the HeartMath program were gained by police officers in the sample, including increased awareness and self-management of stress responses; reduced distress, anger, sadness, and fatigue; reduced sleeplessness and physical stress symptoms; increased peacefulness and vitality; reduced competition within work teams; improved communication within work teams; greater cooperation within work teams; improved work performance; greater confidence, balance, and clarity under acute stress; quicker recalibration following acute stress; and improved listening and relationships with family (McCraty et al., 1999). 
Implementation of the HeartMath program could benefit police officers and their departments in various ways. Potential benefits include enhanced overall health and emotional well-being, work/life balance, organizational climate, and organizational effectiveness and reduced cardiovascular morbidity, early retirement for stress-related causes, and organizational burdens faced by departments (e.g., use of excessive force, work injuries, citizen complaints, lawsuits, liability costs). Overall, the program helps police officers remain balanced when they experience strain and seek appropriate solutions for coping with chronic strain (McCraty et al., 1999).

The Strategic Memory Advanced Reasoning Training (SMART) is a prevention program currently being piloted among a sample of 500 police officers in Dallas, Texas. Developed by the Center for BrainHealth and its Brain Performance Institute at the University of Texas at Dallas, the SMART program offers police officers health enhancing tools designed to assist in their tactical decision-making, real-time problemsolving, and down-regulating emotional reactions to stress. Coupled with a Mindfulness for Law Enforcement component, the goal of the program is to assist police officers in managing their occupational and personal strains (Bishopp et al., 2018; Center for BrainHealth).

The SMART program is based on more than 30 years of neuroscience research and strengthens the brain's intricate frontal lobe networks that govern planning, judgment, decision-making, problem-solving, emotional regulation, and other cognitive functions. The Mindfulness for Law Enforcement component integrates positive psychology with accelerated training and application of mindfulness strategies. Mindfulness is defined as the act of being aware of the present moment without judgment 
or emotional reactivity. Police officers are taught about the science of mindfulness and participate in various mindfulness practices (e.g., guided meditation, body scanning, breathing meditation) (Center for BrainHealth).

Implementation of the SMART program coupled with the Mindfulness for Law Enforcement component could help maximize brain performance, minimize strain, and improve productivity among police officers. Additionally, the program may enhance physical and neural health by altering physiological responses to stress and positively impacting sleep, mood, and life satisfaction. The program may also improve focused attention by promoting cognitive resilience and reducing performance failures (Center for BrainHealth).

\section{Limitations and Directions for Future Research}

While it is believed that the results of the study will contribute to a fuller understanding of the relationships between strain, depression, and substance use as a form of coping among police officers, several limitations must be considered. First, since cross-sectional data were used to examine the relationships among the measures, it prevented the study from taking on a predictive interpretation. Like most studies that used police officer samples to test GST, causation could not be determined among the measures. For example, it was not possible to properly disentangle the causes and consequences of substance use as a form of coping due to the nature of the data. Certain substances (e.g., alcohol, barbiturates, benzodiazepines, cannabis, opioids) have a depressant effect on the central nervous system; thus, heavy use of these substances may cause depression. The current study, however, did not assess measures of actual substance usage (e.g., number of alcoholic drinks per week, amount of marijuana smoked 
per week). In addition, the substance use as coping measure that was examined did not differentiate between the types of substances used as a form of coping, like alcohol, illicit drugs, or prescription drugs among others. In this regard, the current study could not determine whether substance use as a form of coping resulted from strain and depression or if it contributed to strain and depression; results could only be interpreted around the structure of GST. Future longitudinal and multimethod studies that collect detailed data on the timing of events makes it possible to estimate the causal ordering of the measures more accurately.

Second, because the study utilized a sample of police officers working in a large, urban department, results may not be representative of police agencies located in other geographical regions or smaller departments. The generalizability of the results is also limited to occupations that expose employees to significant forms of strain, like social work, military service, and medicine. Replication studies are needed to determine if the results obtained in the study are sample-specific or apply to other departmental contexts. Future studies should test the propositions using a nationally representative sample of police officers from various types and sizes of law enforcement agencies at the local-, state-, and federal-level to broaden generalizability.

Third, social desirability bias is a potential limitation given the sample demographics and research design used in the study. Social desirability bias occurs when individuals respond to questions in a manner that makes them appear in a more favorable light. Participants may have underreported or falsified their responses on the surveys given the sensitivity of the measures. Indeed, some participants may have been reluctant to disclose any history of strain, mental health, or substance use as a form of coping due 
to suspicions and fears of being identified or negatively affected by the department.

Social desirability bias is also more likely to occur in research involving participant selfreport (e.g., surveys, interviews, focus groups). Future studies are encouraged to implement social desirability bias scales to detect, minimize, and correct for social desirability bias to enhance the validity of the measures. Krosnick and Presser (2009) suggested that offering anonymity on self-administered questionnaires using web administration may further reduce social pressure and social desirability bias. Another method for reducing social desirability bias among police officers when examining mental health constructs could be to legitimize less desirable response options. A common approach involves noting in survey questions that many individuals do not engage in socially desirable behavior (Krosnick \& Presser, 2009). For example, researchers could include something like, "In talking with people about their employer, we often find that many people consume alcohol to cope with work-related strains." Finally, improving measurement of key indicators may also reduce social desirability bias. For example, researchers are encouraged to collect objective health, wellness, or performance data (e.g., cortisol test strips, blood pressure, heart rate, physical exam) or outside sources of information (e.g., family members, peers, supervisors) when appropriate.

Fourth, it is also possible that inherent biases in sample selection may have influenced the results. The current study relied on a convenience sample of police officers who attended roll calls, meetings, and trainings. It could be assumed that the experiences of police officers who volunteered to participate in the study may not be representative of the larger population of police officers within the department. It is also 
expected that police officers who engage in more frequent problematic substance use as a form of coping have a greater likelihood of tardiness or being absent from these departmental gatherings. Additionally, the failure to include police officers who were on extended leave (e.g., administrative leave, injury leave, maternity leave, suspension) may have influenced the results. Future efforts should employ random sampling to yield more representative samples of the target population and minimize sampling bias; however, time constraints and limited resources can make it challenging for researchers to execute random sampling.

Fifth, several limitations exist surrounding the measurement of strain, depression, and substance use as a form of coping in the current study. For example, it is possible that the measures included in the analyses were not adequately assessed since they were constructed from surveys that were not originally developed to measure the theoretical concepts of strain, negative affect, and coping described in GST; therefore, the items included in the analyses may only be approximate indicators of the measures. Failure to use validated scales developed specifically for measuring GST's propositions means that other factors could have accounted for some for the observed relationships. For the measurement of strain, the current study did not examine internal or external strains in the context of GST or the various characteristics of strain, such as perceived injustice, magnitude, recency, duration, and clustering of the strainful events and how those might have affected depression and substance use as a form of coping. Additionally, because the sources of strain examined in the study focused on financial problems, time away from family, and media scrutiny, other work-related factors (e.g., lack of organizational support, inadequate equipment, limited opportunities for training or career advancement, 
dangerous work environment) may have influenced participants. The current study also did not incorporate other measures of negative emotional states commonly cited in existing GST literature that may have impacted substance use as a form of coping, such as anger, frustration, fear, and anxiety. Lastly, only one type of coping strategy was examined.

To address the limitations concerning the measurement of strain, depression, and substance use as a form of coping, future studies should employ extensively validated scales that are specifically designed to test the central tenets of GST. Since the data did not allow for the strain measure to be broken down into various internal and external strains, future efforts should consider investigating them within the context of GST since these sources of strain may have different outcomes. Future research should also consider other work-related strains and the perceived injustice, magnitude, recency, duration, and clustering of strainful events experienced by police officers. Examining these dimensions of strain may provide a more comprehensive assessment of GST. Researchers are also encouraged to consider negative emotional states other than depression. For example, future studies could measure the impact of anger, frustration, fear, and anxiety experienced by police officers to more thoroughly test the mediating role of different negative emotional states on the relationship between strain and substance use as a form of coping. Such emotions fall within GST's emphasis on negative emotional states and may direct researchers to investigate other maladaptive consequences of strain. For instance, police officers who experience depression may rely on internalizing, self-destructive forms of coping to alleviate felt strain, like eating orders, suicidal ideation, and cutting. Alternatively, police officers who experience anger 
and frustration may engage in violent or aggressive behavior, such as excessive use of force and officer-on-officer aggression. Likewise, since police officers may respond to strain and depression by engaging in a wide array of behaviors, future investigations should identify other coping strategies that may alleviate or exacerbate felt strain, such as domestic violence, use of force, and gambling among others.

Another suggestion for future research is to evaluate the role of police subculture on the relationship between strain and substance use as a form of coping among police officers. The current study only collected data from a single department; therefore, it was not possible to assess the role of departmental culture. Examining subcultural factors in policing may be essential in understanding the prevalence of substance use among police officers and reluctance of these police officers to seek assistance for coping with strain and substance use. For example, police subculture might condition the experience of strain. It is likely that police officers who work in departments with subcultures that promote substance use are more likely to rely on substances to alleviate strain. Likewise, it is possible that subcultural factors decrease access to positive coping mechanisms that would otherwise make substance use less likely (Swatt et al., 2007).

Although not exhaustive, the above discussion proposed a reasonable research agenda for continued empirical investigation of GST in the context of policing. The nature of police work is stressful so identifying the mechanisms that foster maladaptive coping responses to strain is essential. Despite limitations, the current study provides a useful framework for furthering our understanding of how police officers are impacted by strain and how they may cope with their experiences. 


\section{REFERENCES}

Agnew, R. (1985). A revised strain theory of delinquency. Social Forces, 64(1), 151-167.

Agnew, R. (1989). A longitudinal test of the revised strain theory. Journal of Quantitative Criminology, 5(4), 373-387.

Agnew, R. (1992). Foundation for a general strain theory of crime and delinquency. Criminology,30(1), 47-88.

Agnew, R. (2006). Pressured into crime: An overview of general strain theory. Los Angeles, CA: Roxbury Publishing Company.

Agnew, R., \& White, H. R. (1992). An empirical test of general strain theory. Criminology,30(4),475-499.

Akers, R. (2000). Criminological theories: Introduction, evaluations, and application. Los Angeles, CA: Roxbury Publishing Company.

Akinola, M., \& Mendes, W. B. (2012). Stress-induced cortisol facilitates threat-related decision making among police officers. Behavioral Neuroscience, 126(1), 167174.

Amaranto, E., Steinberg, J., Castellano, C., \& Mitchell, R. (2003). Police stress interventions. Brief Treatment \& Crisis Intervention, 3(1), 47-53.

Anshel, M. H. (2000). A conceptual model and implications for coping with stressful events in police work. Criminal Justice \& Behavior, 27(3), 375-400.

Aseltine, R. H., Gore, S., \& Gordon, J. (2000). Life stress, anger and anxiety, and delinquency: An empirical test of general strain theory. Journal of Health 
Social Behavior, 41(3), 256-275.

Ballenger, J. F., Best, S. R., Metzler, T. J., Wasserman, D. A., Mohr, D. C., Liberman, A., ... Delucchi, K. (2011). Patterns and predictors of alcohol use in male and female urban police officers. American Journal on Addictions, 20(1), 21-29.

Bishop, G. D., Tong, E., Diong, S. M., Enkelmann, H. C., Why, Y. P., Khader, M., \& Ang, J. (2001). The relationship between coping and personality among police officers in Singapore. Journal of Research in Personality, 35(3), 353-374.

Bishopp, S. A., \& Boots, D. P. (2014). General strain theory, exposure to violence, and suicide ideation among police officers: A gendered approach. Journal of Criminal Justice, 42(6),538-548.

Bishopp, S. A., Piquero, N. L., Worrall, J. L., \& Piquero, A. R. (2018). Negative affective responses to stress among urban police officers: A general strain theory approach. Deviant Behavior, 1-20.

Burke, K. J., \& Paton, D. (2006). Well-being in protective services personnel: Organisational influences. Australasian Journal of Disaster \& Trauma Studies, 2(2).

Carver, C. S., Scheier, M. F., \& Weintraub, J. K. (1989). Assessing coping strategies: A theoretically based approach. Journal of Personality \& Social Psychology, 56(2), 267-283.

Center for BrainHealth, The University of Texas at Dallas. (n.d.). Center for BrainHealth and Dallas Police Department partner to advance brain health of police office. 
Retrieved from https://brainhealth.utdallas.edu/center-for-brainhealth-and-dallaspd-partner-to-advance-brain-health/

Chapin, M., Brannen, S. J., Singer, M. I., \& Walker, M. (2008). Training police leadership to recognize and address operational stress. Police Quarterly, 11(3), $338-352$.

Cheng, M. K. (2006). Structural equation modeling of the restructured clinical scales of the MMPI-2 (Unpublished doctoral dissertation). University of Windsor, Windsor, Ontario, Canada.

Chopko, B. A., Palmieri, P. A., \& Adams, R. E. (2013). Associations between police stress and alcohol use: Implications for practice. Journal of Loss \& Trauma, 18(5), 482-497.

Chrismas, R. (2012). An arranged marriage: Police-media conflict and collaboration. Canadian Graduate Journal of Sociology \& Criminology, 1(1), 4355.

Davey, J. D., Obst, P. L., \& Sheehan, M. C. (2000). Developing a profile of alcohol consumption patterns of police officers in a large-scale sample of an Australian police service. European Addiction Research, 6(4), 205-212.

Dietrich, J., \& Smith, J. (1986). The non-medical use of drugs including alcohol among police personnel: A critical literature review. Journal of Police Science \& Administration, 14(4), 300-306.

Donnelly, E., Valentine, C., \& Oehme, K. (2015). Law enforcement officers and employee assistance programs. Policing: An International Journal of Police Strategies \& Management, 38(2), 206-220. 
Durkheim, E. (1893). The division of labor in society (G. Simpson, Trans; 1933 edition). New York, NY: The Macmillan Company.

Gershon, R. M., Lin, S., \& Li, X. (2002). Work stress in aging police officers. Journal of Occupational \& Environmental Medicine, 44(2), 160-167.

Gibson, C. L., Swatt, M. L., \& Jolicoeur, J. R. (2001). Assessing the generality of general strain theory: The relationship among occupational stress experienced by male police officers and domestic forms of violence. Journal of Crime \& Justice, 24(2), 29-57.

Hay, C., \& Evans, M. M. (2006). Violent victimization and involvement in delinquency: Examining predictions from general strain theory. Journal of Criminal Justice, 34(3), 261-274.

Haisch, D. C., \& Meyers, L. S. (2004). MMPI-2 assessed post-traumatic stress disorder related to job stress, coping, and personality in police agencies. Stress \& Health, 20(4), 223-229.

Hauke, J., \& Kossowski, T. (2011). Comparison of values of Pearson's and Spearman's correlation coefficients on the same sets of data. Quaestiones Geographicae, 30(2), 87-93.

Hickman, M. J., Fricas, J., Strom, K. J., \& Pope, M. W. (2011). Mapping police stress. Police Quarterly, 14 (3), 227-250.

High, L. R. (2015). Evaluation of validity and reliability of the High Stress Inventory in a college population (Unpublished doctoral dissertation). Spalding University, Louisville, KY.

Hoffman, J. P., \& Miller, A. S. (1998). A latent variable analysis of general strain theory. 
Journal of Quantitative Criminology, 14(1), 83-110.

Holgado-Tello, F. P., Chacon-Moscoso, S., Barbero-Garcia, I., \& Vila-Abad, E. (2010). Polychoric versus Pearson correlations in exploratory and confirmatory factor analysis of ordinal variables. Quality \& Quantity, 44(1), 153-166.

Hooper, D., Coughlan, J., \& Mullen, M. (2008). Structural equation modelling:

Guidelines for determining model fit. Journal of Business Research Methods, $6(1), 53-60$.

Kline, R. B. (2016). Principles and practice of structural equation modeling ( $4^{\text {th }}$ ed.). New York, NY: The Guilford Press.

Krosnick, J. A., \& Presser, S. (2009). Question and questionnaire design. In Handbook of survey research (2nd ed., pp. 1-81). San Diego, CA: Elsevier.

Kurtz, D. L., Zavala, E., \& Melander, L. A. (2015). The influence of early strain on later strain, stress responses, and aggression by police officers. Criminal Justice Review, 40(2), 190-208.

Lee, S. G., Kim, I., \& Kim, D. (2014). Workplace violence and depressive symptomatology among police officer. Occupational \& Environmental Medicine, 71 Suppl: A76.

Litman, J. A. (2006). The COPE Inventory: Dimensionality and relationships with approach-and avoidance-motives and positive and negative traits. Personality \& Individual Differences, 41(1), 273-284.

Louw, G. J., \& Viviers, A. (2010). An evaluation of a psychosocial stress and coping model in the police work context. SA Journal of Industrial Psychology, 36(1), 111. 
Manzoni, P., \& Eisner, M. (2006). Violence between the police and the public: Influences of work-related stress, job satisfaction, burnout, and situational factors. Criminal Justice \& Behavior, 33(5), 613-645.

Maxfield, M. G., \& Babbie, E. R. (2015). Research methods for criminal justice and Criminology $\left(7^{\text {th }}\right.$ ed.). Stanford, CT: Cengage Learning.

McCraty, R., Tomasino, D., Atkinson, M., \& Sundram, J. (1999). Impact of the HeartMath self-management skills program on physiological and psychological stress in police officers. (Publication No. 99-075) Boulder, Creek, CA: HeartMath Research Center, Institute of HeartMath.

Merton, R. K. (1938). Social structure and anomie. American Sociological Review, 3(5), $672-682$.

Moon, B., Hays, K., \& Blurton, D. (2009). General strain theory, key strains, and deviance. Journal of Criminal Justice, 37(1), 98-106.

Moon, M. M., \& Jonson, C. L. (2012). The influence of occupational strain on organizational commitment among police: A general strain theory approach. Journal of Criminal Justice, 40(3), 249-258.

National Institute of Mental Health Office of Science Policy, Planning, and Communications. (2017, January). Men and depression. Retrieved from https://www.nimh.nih.gov/health/publications/men-and-depression/index.shtml

Nelson, K.V., \& Smith, A. P. (2106). Occupational stress, coping, and mental health in Jamaican police officers. Occupational Medicine, 66(6), 488-491.

Parnaby, P. F., \& Leyden, M. (2011). Dirty harry and the station queens: A Mertonian analysis of police deviance. Policing \& Society, 21(3), 249-264. 
Peterson, R. A. (1994). A meta-analysis of Cronbach's coefficient alpha. Journal of Consumer Research, 21(2), 381-391.

Pratt, T. C., \& Cullen, F. T. (2005). Assessing macro-level predictors and theories of crime: A meta-analysis. Crime \& Justice, 32, 373-450.

Raykov, T., \& Marcoulides, G. A. (2006) A first course in structural equation modeling. ( $2^{\text {nd }}$ ed.). Mahwah, NJ: Lawrence Erlbaum Associates, Inc.

Richmond, R., Wodak, A., Kehoe, L., \& Heather, N. (1998). How healthy are the police? A survey of lifestyle factors. Addiction, 93(11), 1729-1737.

Russell, L. M. (2014). An empirical investigation of high-risk occupations: Leader influence on employee stress and burnout among police. Management Research Review, 37(4), 367-384.

Shim, H. S., Jo, Y., \& Hoover, L. T. (2015). A test of general strain theory on police officers' turnover intention. Asian Criminology, 10(1), 43-62.

Sigfusdottir, I. D., Kristjansson, A. L., \& Agnew, R. (2012). A comparative analysis of general strain theory. Journal of Criminal Justice, 40(2), 117-127.

Simpson, S. S., \& Weisburd, D. (Eds.). (2009). The criminology of white-collar crime. New York, NY: Springer.

Smith, D. R., Devine, S., Leggat, P. A., \& Ishitake, T. A. (2005). Alcohol and tobacco consumption among police officers. Kurume Medical Journal, 52(1-2), 63-65.

Spina, E. (2005). Perception of stress with law enforcement personnel (Unpublished doctoral dissertation). Carlos Albizu University, Miami, FL.

Swatt, M. L., Gibson, C. L., \& Piquero, N. L. (2007). Exploring the utility of general strain theory in explaining problematic alcohol consumption by police 
officers. Journal of Criminal Justice, 35(6), 596-611.

United States Department of Justice. Office of Justice Programs. Bureau of Justice Statistics. (2015). Law enforcement management and administrative statistics (LEMAS), 2013 [data file and codebook]. Ann Arbor, MI: Inter-University Consortium for Political and Social Research [distributor].

Van Raalte, R. (1979). Alcoholism as a problem among officers. Police Chief, 46, 38-39.

Violanti, J. M., Slaven, J. E., Charles, L. E., Burchfiel, C. M., Andrew, M. E., \& Homish, G. G. (2011). Police and alcohol use: A descriptive analysis and associations with stress outcomes. American Journal of Criminal Justice, 36(4), 344-356.

Vito, G. F., Blankenship, M. B., \& Kunselman, J. C. (2008). Statistical analysis in criminal justice and criminology: A user's guide ( $2^{\text {nd }}$ ed.). Long Grove, IL: Waveland Press, Inc.

Wukasch, B. C. (2017). Financial and pre-retirement planning for law enforcement officers (Unpublished white paper). The Bill Blackwood Law Enforcement Management Institute of Texas, Cedar Park, TX.

Wang, Z., Inslicht, S. S., Metzler, T. J., Henn-Haase, C., McCaslin, S. E., Tong, H., ... Marmar, C. R. (2010). A prospective study of predictors of depression symptoms in police. Psychiatry Research, 175(3), 211-216.

Wilson, H. (2015). Police officer's perception of stress: A scale development study (Unpublished doctoral dissertation). Spalding University, Louisville, KY.

Yu, H., Jiang, S., \& Land, K. C. (2015). Multicollinearity in hierarchical linear models. Social Science Research, 53, 118-136. 
Yun, I., \& Lee, C. H. (2015). Hazardous alcohol use among South Korean police officers: Examining predictions from general strain theory. International Journal of Law, Crime, \& Justice, 43(2), 194-213. 


\section{CURRICULUM VITAE}

Kyra N. Fritz

Pacific Institute for Research and Evaluation (PIRE)

Louisville, KY 40202

Office: (502) 238-7333

kfritz@pire.org

\section{EDUCATION}

2019 Ph.D. University of Louisville - Criminal Justice

Dissertation Title: Police Stress, Depression, and Substance Use among Police Officers: A General Strain Perspective

2016 MA Spalding University - Clinical Psychology

2011 BA University of Kansas - Psychology

\section{PROFESSIONAL WORK EXPERIENCE}

$\begin{array}{ll}2013-\text { Present } & \begin{array}{l}\text { Research Associate II } \\ \text { Pacific Institute for Research and Evaluation (PIRE) } \\ \text { Louisville, KY }\end{array} \\ 2015-2016 & \begin{array}{l}\text { Intern Therapist } \\ \text { Communicare Behavioral Health Clinic } \\ \text { Leitchfield, KY }\end{array} \\ & \text { Intern Therapist } \\ & \text { Groupworks } \\ & \text { Louisville, KY } \\ & \text { Intern Therapist } \\ & \text { Central State Hospital } \\ & \text { Louisville, KY }\end{array}$


Intern

Lawrence Police Department

Lawrence, KS

\section{HONORS / AWARDS}

\begin{tabular}{|c|c|}
\hline 2017 - Present & $\begin{array}{l}\text { Alpha Phi Sigma (National Honor Society) } \\
\text { University of Louisville } \\
\text { Louisville, KY }\end{array}$ \\
\hline 2017 - Present & $\begin{array}{l}\text { Tau Sigma (National Honor Society) } \\
\text { University of Louisville } \\
\text { Louisville, KY }\end{array}$ \\
\hline $2017-2018$ & $\begin{array}{l}\text { Tau Sigma Executive Board (National Honor Society) } \\
\text { University of Louisville } \\
\text { Louisville, KY }\end{array}$ \\
\hline 2017 & $\begin{array}{l}\text { Graduate Assistantship Award (Ph.D.) } \\
\text { Department of Criminal Justice } \\
\text { University of Louisville } \\
\text { Louisville, KY }\end{array}$ \\
\hline $2013-2016$ & $\begin{array}{l}\text { Psi Chi (National Honor Society) } \\
\text { Spalding University } \\
\text { Louisville, KY }\end{array}$ \\
\hline $2015-2016$ & $\begin{array}{l}\text { Psi Chi Executive Board (National Honor Society) } \\
\text { Spalding University } \\
\text { Louisville, KY }\end{array}$ \\
\hline
\end{tabular}

\section{PUBLICATIONS}

Fritz, K. \& Lim, N. K. (2018). "Selection Bias.” In Bruce Frey (Ph.D.), Encyclopedia of Educational Research, Measurement, \& Evaluation. Sage Publications.

\section{CONFERENCE / POSTER PRESENTATIONS}

Myers, K., Luongo, K., Lim, N. K., \& Denton, B. "Validity of the P-NORAB with Law Enforcement Personnel." Poster presentation at American Psychological Association Annual Conference, Chicago, IL, August 2019. 
Losavio, M., Hinton, J., Fritz, K., Lauf, A., Hieb, J., Im, G.,...Bergman, M. "STEM for Public Safety in Cyber: STEM Training for Local Law Enforcement and Cyber Security." Paper presentation at IEEE Integrated STEM Education Conference, Princeton, NJ, March 2019.

Fritz, K. "The unique experiences of women in law enforcement." Paper presentation at University of Louisville, Louisville, KY, April 2017.

\section{VOLUNTEER EXPERIENCE}

$2014-2016$

$2015-2016$

$2015-2016$

2014

$2006-2007$
Psy.D. Student Interviewer

Spalding University

Louisville, KY

Pay It Forward Program Mentor

Spalding University

Louisville, KY

School of Professional Psychology Peer Advisor

Spalding University

Louisville, KY

Graduate School Information Booth Student Representative

Kentucky Psychological Association

Wilmore, KY

Student Ambassador

University of Kansas

Lawrence, KS

PROFESSIONAL ASSOCIATIONS

\begin{tabular}{|c|c|}
\hline 2016 - Present & Academy of Criminal Justice Sciences \\
\hline 2016 - Present & American Society of Criminology \\
\hline 2016 - Present & Southern Criminal Justice Association \\
\hline $2013-2016$ & American Psychological Association \\
\hline $2015-2016$ & Kentucky Psychological Association Executive Board \\
\hline $2013-2016$ & Kentucky Psychological Association \\
\hline
\end{tabular}




\section{EXTRACURRICULUAR ACTIVITIES}

2013 - $2016 \quad$ Citizen's Police Academy

Louisville Metro Police Department

Louisville, KY

Last Update: November 2019 